ARTICLE

https://doi.org/10.1038/s41467-021-21005-w

\title{
The mechanism of the nucleo-sugar selection by multi-subunit RNA polymerases
}

\author{
Janne J. Mäkinen (10 1, Yeonoh Shin (1) 2 , Eeva Vieras', Pasi Virta (i) ${ }^{3}$, Mikko Metsä-Ketelä (1) 1, \\ Katsuhiko S. Murakami (i) ${ }^{2 凶} \&$ Georgiy A. Belogurov (i] ${ }^{1 凶}$
}

RNA polymerases (RNAPs) synthesize RNA from NTPs, whereas DNA polymerases synthesize DNA from 2'dNTPs. DNA polymerases select against NTPs by using steric gates to exclude the $2^{\prime} \mathrm{OH}$, but RNAPs have to employ alternative selection strategies. In singlesubunit RNAPs, a conserved Tyr residue discriminates against 2'dNTPs, whereas selectivity mechanisms of multi-subunit RNAPs remain hitherto unknown. Here, we show that a conserved Arg residue uses a two-pronged strategy to select against 2 'dNTPs in multi-subunit RNAPs. The conserved Arg interacts with the $2^{\prime} \mathrm{OH}$ group to promote NTP binding, but selectively inhibits incorporation of $2^{\prime}$ dNTPs by interacting with their $3^{\prime} \mathrm{OH}$ group to favor the catalytically-inert 2 '-endo conformation of the deoxyribose moiety. This deformative action is an elegant example of an active selection against a substrate that is a substructure of the correct substrate. Our findings provide important insights into the evolutionary origins of biopolymers and the design of selective inhibitors of viral RNAPs.

\footnotetext{
${ }^{1}$ Department of Biochemistry, University of Turku, Turku, Finland. ${ }^{2}$ Department of Biochemistry and Molecular Biology, The Center for RNA Molecular Biology, The Pennsylvania State University, University Park, PA, USA. ${ }^{3}$ Department of Chemistry, University of Turku, Turku, Finland.

凶email: kum14@psu.edu; gebelo@utu.fi
} 
A ll cellular lifeforms use two types of nucleic acids, RNA and DNA to store, propagate, and utilize their genetic information. RNA polymerases (RNAPs) synthesize RNA from ribonucleoside triphosphates (NTPs), whereas DNA polymerases (DNAPs) use $2^{\prime}$-deoxyribonucleoside triphosphates $\left(2^{\prime}\right.$ dNTPs) to synthesize DNA. The RNA building blocks precede the DNA building blocks biosynthetically and possibly also evolutionarily ${ }^{1,2}$. Messenger RNA molecules function as information carriers in a single-stranded form, whereas ribosomal, transfer and regulatory RNAs adopt complex three-dimensional structures composed of double-stranded segments. The doublestranded RNAs favor A-form geometry where the ribose moiety of each nucleotide adopts the $3^{\prime}$-endo conformation (Fig. 1a). In contrast, DNA functions as a B-form double helix, where the deoxyribose of each nucleotide adopts the 2 -endo conformation (Fig. 1a, b). Hybrid duplexes between the RNA and DNA transiently form during transcription and adopt an A-form geometry because conformational preferences of the RNA strand outweigh those of a more flexible DNA strand. The sugar moieties of NTPs and $2^{\prime} \mathrm{dNTPs}$ equilibrate freely between the $3^{\prime}$ - and $2^{\prime}$-endo conformations in solution with the overall bias typically shifted toward the $2^{\prime}$-endo conformers ${ }^{3}$. However, both NTPs and $2^{\prime}$
dNTPs typically adopt the $3^{\prime}$-endo conformation in the active sites of the nucleic acid polymerases ${ }^{4}$.

RNAPs and DNAPs need to discriminate efficiently against the substrates with the non-cognate sugar. The intracellular levels of NTPs are in the range of hundreds of micromoles to several millimoles per liter and exceed those of the corresponding $2^{\prime}$ dNTPs more than 10 -fold ${ }^{5-7}$. Most DNAPs use bulky side-chain residues in their active sites to exclude the $2^{\prime} \mathrm{OH}$ of NTPs (reviewed in ref. ${ }^{8}$ ). The steric gate residue, typically Gln/Glu in A-family DNAPs and Tyr/Phe in Y- and B-family DNAPs, stretches along the $\alpha$-face of the deoxyribose moiety of an incoming 2 dNTP and forms a hydrogen bond between the backbone amide group and the $3^{\prime}-\mathrm{OH}$ group of $2^{\prime} \mathrm{dNTP}$ (Fig. 1c).

Selection against $2^{\prime}$ dNTPs by RNAPs is a daunting challenge because $2^{\prime}$ dNTPs are substructures of the corresponding NTPs. Single-subunit RNAPs (e.g., mitochondrial and bacteriophage T7 and N4 enzymes) are homologous and structurally similar to DNAPs. However, single-subunit RNAPs lack a steric gate and use a conserved Tyr residue to discriminate against $2^{\prime} \mathrm{dNTPs}^{9,10}$. Tyr forms a hydrogen bond with the $2^{\prime} \mathrm{OH}$ group of the NTP ribose (Fig. 1c) $)^{11,12}$ but mediates the selectivity by inhibiting the binding and incorporation of $2^{\prime} \mathrm{dNTP}^{9,13}$. It is hypothesized that a

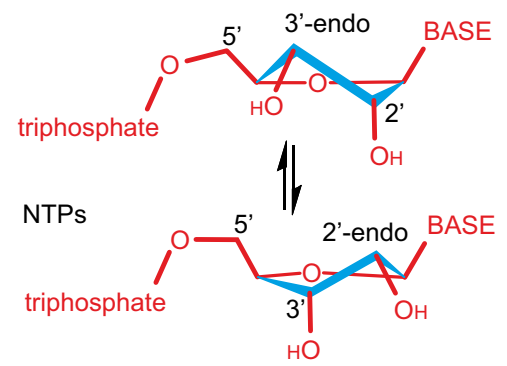

In solution only, B-form duplex unfavorable

In solution and in A-form duplex (as 2'dNMP)

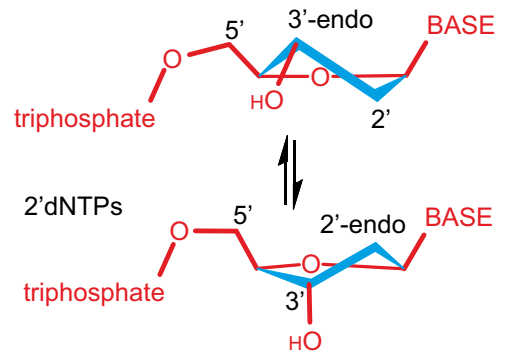

In solution and in B-form duplex (as 2'dNMP)

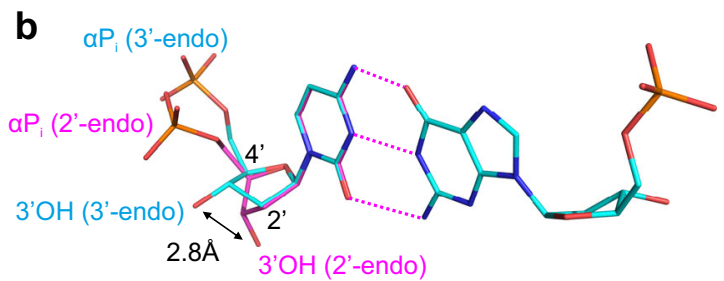

C

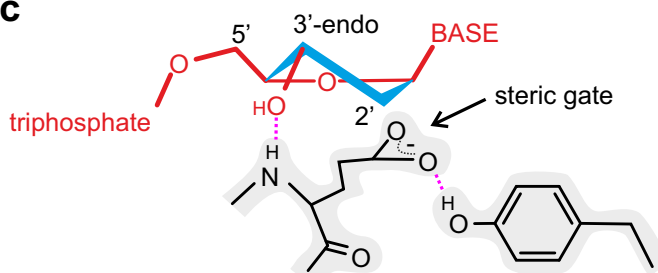

Family-A DNAPs

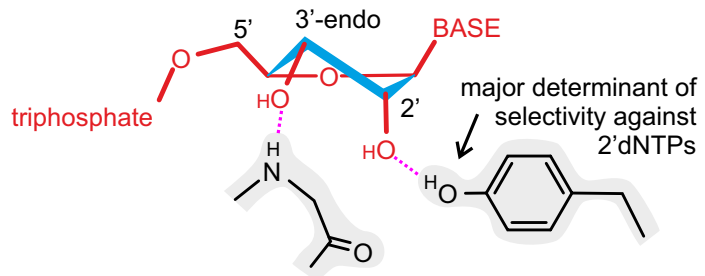

Bacteriophage T7 and mitochondrial RNAPs

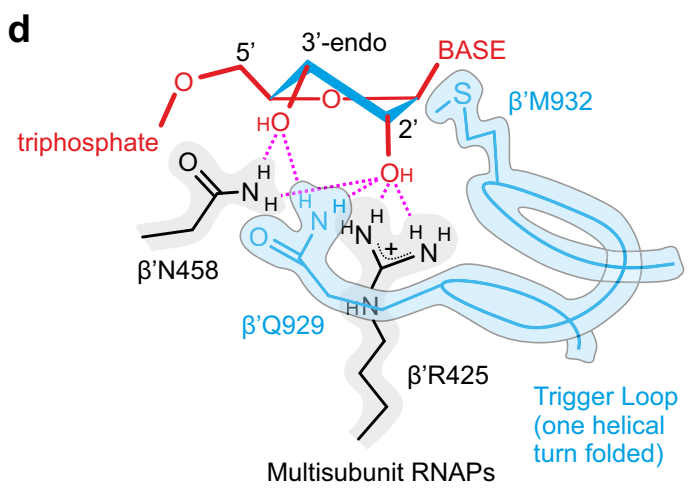

Fig. 1 Recognition of NTPs and 2' dNTPs by nucleic acid polymerases. a NTPs and 2'dNTPs equilibrate freely between $3^{\prime}$-endo and 2'-endo conformations in solution. A- and B-form duplexes of RNA and DNA constrain sugar moieties of nucleotides in $3^{\prime}$-endo and $2^{\prime}$-endo conformations, respectively. $\mathrm{C}^{\prime}-\mathrm{C} 2^{\prime}-\mathrm{C} 3^{\prime}-\mathrm{C} 4^{\prime}$ bonds of the sugar moieties are colored cyan. b Watson-Crick base pairing of the $3^{\prime}$-endo (cyan) and 2'-endo (magenta) conformers to the template nucleic acid results in markedly different positions of the $3^{\prime} \mathrm{OH}$ group and the $\alpha$-phosphate relative to the base-pairing plane. $\mathbf{c}$, $\mathbf{d}$ DNAPs and RNAPs stabilize 3 '-endo conformers of their cognate substrates. The illustrations reflect the crystallographically documented arrangement of the active site residues but are not accurate projections of 3D structures. Dashed magenta lines depict polar interactions and hydrogen bonds. 
the formation of the Tyr $-2^{\prime} \mathrm{OH}$ hydrogen bond upon the binding of NTPs counteracts an inhibitory interaction of the Tyr with another residue or a water molecule ${ }^{10}$. Noteworthy, a homologous Tyr hydrogen bonds with the steric gate Gln/Glu residue in A-family DNAPs (Fig. 1c) $)^{14,15}$.

The mechanism of discrimination against $2^{\prime}$ dNTPs by the multi-subunit RNAPs (bacterial, archaeal, and eukaryotic nuclear RNAPs) is poorly understood. The combined structural evidence (reviewed in ref. ${ }^{16}$ ) suggests that the $2^{\prime} \mathrm{OH}$ group can make polar contacts with three universally conserved amino acid side chains: $\beta^{\prime} \operatorname{Arg} 425, \beta^{\prime} A s n 458$, and $\beta^{\prime}$ Gln929 (numbering of the Escherichia coli RNAP). $\beta^{\prime} \operatorname{Arg} 425$ and $\beta^{\prime}$ Asn 458 belong to the active site cavity and can interact with the $2^{\prime} \mathrm{OH}$ of NTPs in the open and closed active site (see below), whereas $\beta^{\prime}$ Gln 929 is contributed by a mobile domain called the trigger loop (TL) and can only transiently interact with the $2^{\prime}-$ and $3^{\prime}-\mathrm{OH}$ of NTPs in the semiclosed active $\operatorname{site}^{17-19}$ (Fig. 1d). Closure of the active site by the folding of two alpha-helical turns of the TL positions the triphosphate moiety of the substrate NTP inline for an attack by the $3^{\prime} \mathrm{OH}$ group of the RNA and accelerates catalysis $\sim 10^{4}$ fold ${ }^{20-23}$. However, most structures of RNAP complexes with NTP analogs feature a semi-closed active site where the TL is helical up to $\beta^{\prime}$ Met932 (refs. ${ }^{17-19}$ ) (Supplementary Table 1). Partial folding of the TL establishes contacts between $\beta^{\prime} G \ln 929$ and the ribose moiety and stacking of $\beta^{\prime}$ Met932 with the nucleobase (Fig. 1d) but is insufficient to promote catalysis $\left(3^{\prime} \mathrm{OH} \rightarrow a \mathrm{P}\right.$ distance $5.4 \AA^{18}$ ).

The relative contribution of the TL ( $\beta^{\prime}$ Gln929 and $\beta^{\prime}$ Met932) and the active site cavity ( $\beta^{\prime} \operatorname{Arg} 425$ and $\beta^{\prime}$ Asn 458$)$ to the discrimination against $2^{\prime}$ dNTPs remains hitherto uncertain. The closure of the active site makes only a 5 - to 10 -fold contribution to an overall 500- to 5000-fold selectivity in RNAPs from E. coli ${ }^{23}$ and Saccharomyces cerevisiae ${ }^{24}$. Consistently, the open active site of the $E$. coli RNAP retained a $\sim 100$-fold overall selectivity against $2^{\prime} \mathrm{dNTP}^{23}$. However, the open active site of the Thermus aquaticus RNAP has been reported to be largely unselective ${ }^{22}$, and individual substitutions of the $\beta^{\prime}$ Asn 458 with Ser in E. coli and $S$. cerevisiae reduced selectivity less than 5 -fold ${ }^{20,25}$. Most importantly, although the universally conserved $\beta^{\prime} A r g 425$ closely approaches $2^{\prime} \mathrm{OH}$ of the NTP in several X-ray crystal structures $^{17-20,26}$ (Supplementary Table 1 ) and has been highlighted as the sole residue mediating the selectivity against $2^{\prime}$ dNTP in a computational study by Roßbach and Ochsenfeld ${ }^{27}$, its role has not been experimentally assessed.

In this study, we systematically investigated the effects of individual substitutions of the active site residues on the discrimination against $2^{\prime}$ dNTPs in single nucleotide addition (SNA) assays and during processive transcript elongation by the E. coli RNAP. This analysis demonstrated that $\beta^{\prime} \operatorname{Arg} 425$ is the major determinant of the selectivity against 2 dNTPs. We further analyzed the binding of $2^{\prime}$-deoxy substrates by in silico docking and X-ray crystallography of Thermus thermophilus RNAP. Our data suggest that the conserved Arg actively selects against 2'dNTPs by favoring their templated binding in the $2^{\prime}$-endo conformation that is poorly suitable for incorporation into RNA.

\section{Results}

$\beta^{\prime} \operatorname{Arg} 425$ is the major determinant of the selectivity against $2^{\prime}$ dGTP by $\boldsymbol{E}$. coli RNAP. To investigate the mechanism of the discrimination against the 2'-deoxy substrates, we performed time-resolved measurements of the single nucleotide incorporation by the wild-type (WT) and variant E. coli RNAPs. Among several single substitutions of the key residues that contact NTP ribose (Fig. 1d), we selected four variant RNAPs that retained at least half of the WT activity at saturating concentration of NTPs. This approach minimized the possibility that the amino acid substitutions induced global rearrangements of the active site thereby complicating the interpretations of their effects on the sugar selectivity.

Transcription elongation complexes (TECs) were assembled on synthetic nucleic acid scaffolds and they contained the fully complementary transcription bubble flanked by 20 -nucleotide DNA duplexes upstream and downstream (Fig. 2a). The annealing region of a 16-nucleotide RNA primer was initially 9 nucleotides, permitting the TEC extended by one nucleotide to adopt the postand pre-translocated states, but disfavoring backtracking ${ }^{28}$. The RNA primer was $5^{\prime}$ labeled with the infrared fluorophore ATTO680 to monitor the RNA extension by denaturing PAGE. The template DNA strand contained the fluorescent base analog 6-methyl-isoxanthopterin (6-MI) eight nucleotides upstream from the RNA $3^{\prime}$ end to monitor RNAP translocation along the DNA following nucleotide incorporation ${ }^{29}$.

We first measured GTP and $2^{\prime}$ dGTP concentration series of the WT and altered RNAPs using a time-resolved fluorescence assay performed in a stopped-flow instrument (Fig. 2b, c). We used the translocation assay because it allowed rapid acquisition of concentration series, whereas measurements of concentration series by monitoring RNA extension in the rapid chemical quench-flow setup would be considerably more laborious. The concentration series data allowed the estimation of $k_{\text {cat }}$ and the $\mathrm{Km}$ (Michaelis constant) for GTP and $2^{\prime}$ dGTP. We then supplemented the concentration series with time-courses of GMP and 2'dGMP incorporation obtained using a rapid chemical quench-flow technique with EDTA as a quencher. EDTA inactivates the free GTP and $2^{\prime} \mathrm{dGTP}$ by chelating $\mathrm{Mg}^{2+}$ but allows a fraction of the already bound substrate to complete incorporation into $\mathrm{RNA}^{30,31}$. The EDTA quench experiment is thus equivalent to a pulse-chase setup and provides information about the rate of substrate dissociation from the active site of RNAP. A global analysis of the concentration series and EDTA quench experiments (i) allowed the estimation of the $K_{\mathrm{D}}$ for GTP dissociation from the active site and (ii) suggested that the $K_{\mathrm{D}}$ for the dissociation of $2^{\prime} \mathrm{dGTP}$ from the active site approximately equals the $K m$ for $2^{\prime}$ dGMP incorporation (see Supplementary Note). We further used inferred values of $k_{\text {cat }}$ and $K_{\mathrm{D}}$ to compare the capabilities of the variant RNAPs to discriminate against $2^{\prime}$ dGTP (Fig. 3).

WT RNAP displayed $\sim 60$-fold higher affinity for GTP than for 2'dGTP (Fig. 3a and Table 1). The $\beta^{\prime} \mathrm{R} 425 \mathrm{~K}$ and $\beta^{\prime} \mathrm{Q} 929 \mathrm{M}$ substitutions decreased the selectivity at the binding step 17-and 30 -fold, respectively, largely by decreasing the affinity for GTP. In contrast, $\beta^{\prime} \mathrm{N} 458 \mathrm{~S}$ decreased the selectivity only 4 -fold, whereas $\beta^{\prime}$ M932A increased the selectivity 2.5 -fold. At saturating substrate concentrations, the WT RNAP incorporated GMP $\sim 50$-fold faster than $2^{\prime} \mathrm{dGMP}$ (Fig. $3 \mathrm{~b}$ and Table 1 ). The $\beta^{\prime} \mathrm{R} 425 \mathrm{~K}$ substitution decreased the selectivity 25 -fold, primarily by accelerating the $2^{\prime}$ dGMP incorporation. In comparison, the effects of other substitutions at the incorporation step were relatively small (Fig. 3b, Table 2, and Supplementary Table 2). $\beta^{\prime} \mathrm{M} 932 \mathrm{~A}$ decreased the selectivity 3 -fold, whereas $\beta^{\prime} \mathrm{N} 458 \mathrm{~S}$ and $\beta^{\prime} \mathrm{Q} 929 \mathrm{M}$ increased the selectivity 1.5 - and 4 -fold, respectively. Noteworthy, $\beta^{\prime} \mathrm{Q} 929 \mathrm{M}$ decreased the rate of $2^{\prime} \mathrm{dGMP}$ incorporation 10 -fold.

Overall, these experiments suggested that the $\beta^{\prime}$ Arg 425 residue plays a central role in the discrimination against $2^{\prime}$-deoxy substrates: $\beta^{\prime}$ Arg425 selectively facilitated binding of GTP and selectively inhibited the incorporation of $2^{\prime} \mathrm{dGMP}$. In contrast, the role of $\beta^{\prime} \mathrm{Gln} 929$ was complex: while $\beta^{\prime} \mathrm{G} \ln 929$ selectively facilitated the binding of GTP, it also selectively facilitated the incorporation of $2^{\prime} \mathrm{dGMP}$. 
a

$$
\begin{aligned}
& \text { S042 5'-ACtTGtAGCGATCtAAGgtT CCAGAGGAGG CATCATGTCAGTAGAGTAGC-3' } \\
& \text { S041M 3'-TGAACATCGCTAGATTCCAAGQTCTCCTCCGTAGTACAGTCATCTCATCG-5' } \\
& \text { R024 Atto680-CUCACAA CCAGAGGAG } \quad \nabla=6-\mathrm{MI}
\end{aligned}
$$

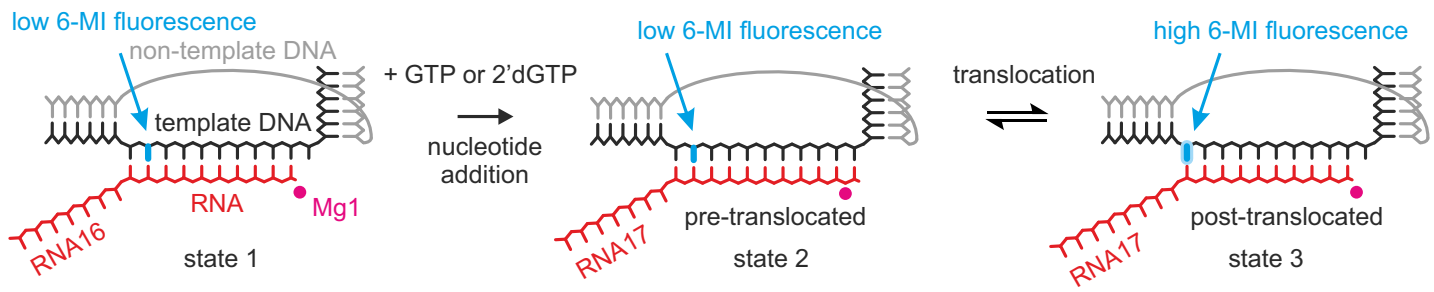

b
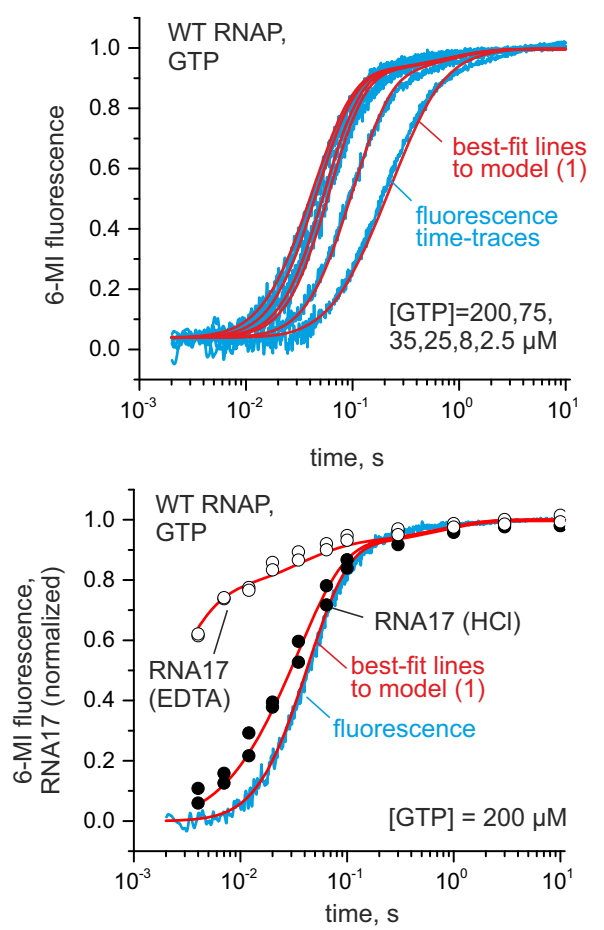

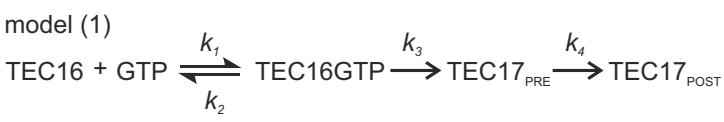

C
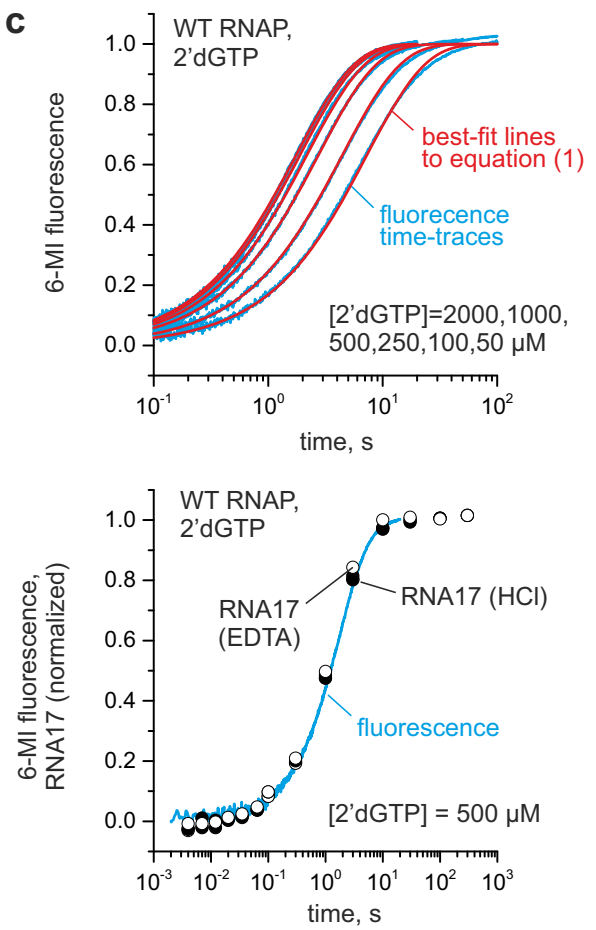

equation (1)

$F(t)=1-e^{-\left(k_{a p p} \times t\right)^{\beta}} \quad k_{a p p}=\frac{k_{3}}{1+\frac{K_{m}}{\left[2^{\prime} \mathrm{dGTP}\right]}}$

Fig. 2 Time-resolved measurements of GTP and 2'dGTP utilization by the WT E. coli RNAP. a The nucleic acid scaffold employed in translocation and nucleotide addition assays. The fluorescence of a guanine analog 6-MI (cyan) was quenched by neighboring base pairs in the initial TEC (state 1) and the pre-translocated TEC that formed following the nucleotide incorporation (state 2) but increased when the 6-MI relocated to the edge of the RNA:DNA hybrid upon translocation (state 3). The template DNA, non-template DNA, RNA, and the catalytic Mg2+ ions are colored black, gray, red, and magenta, respectively. b GTP concentration series. The data were fit to model (1). c 2'dGTP concentration series. The data were fit to equation (1). The best-fit lines and fluorescence time-traces are colored red and cyan, respectively. The $\mathrm{HCl}$ and EDTA quenched data points are shown as closed and opened circles, respectively. All experiments were performed in duplicate with similar results, duplicate data were combined for the analysis. Source data are provided as a Source Data file.

$\beta^{\prime}$ Arg425 inhibits the utilization of $\mathbf{2}^{\prime} \mathrm{dNTPs}$ during processive transcript elongation. The time-resolved SNA assays described above are superior to any other currently available techniques for the quantitative assessment of the binding and incorporation of different substrates and the effects of active site residues therein. However, these assays have several limitations: the nucleotide incorporation was measured for static complexes stabilized in the post-translocated state by the artificially limited RNA:DNA complementarity and the effects are assessed only at a single, easy to transcribe, sequence position. To test if the conclusions drawn from the SNA assay remain valid during processive transcript elongation, we developed a semi-quantitative assay as follows.
TECs were assembled on a nucleic acid scaffold with a 49-bplong downstream DNA and chased with NTP mixtures containing $50 \mu \mathrm{M}$ ATP, CTP, UTP, and GTP or $2^{\prime}$ dGTP for 2 min at $25^{\circ} \mathrm{C}$. Transcription with $2^{\prime} \mathrm{dGTP}$ by the WT RNAP resulted in characteristic pauses at each sequence position preceding the incorporation of $2^{\prime}$ dGMP (Fig. 4, pre-G sites). We used the amplitude of these accumulations as a semi-quantitative measure of the ability of RNAP to utilize 2 'dGTP. Noteworthy, the interpretation of the processive transcription by some variant RNAPs was complicated by enhanced pausing after the incorporation of cytosine (Fig. 4b, at-C sites) and $2^{\prime}$ dGMP (Fig. 4b, at-G sites) in certain sequence contexts. However, these additional pauses were unrelated to the utilization of $2^{\prime} \mathrm{dGTP}$ as a 

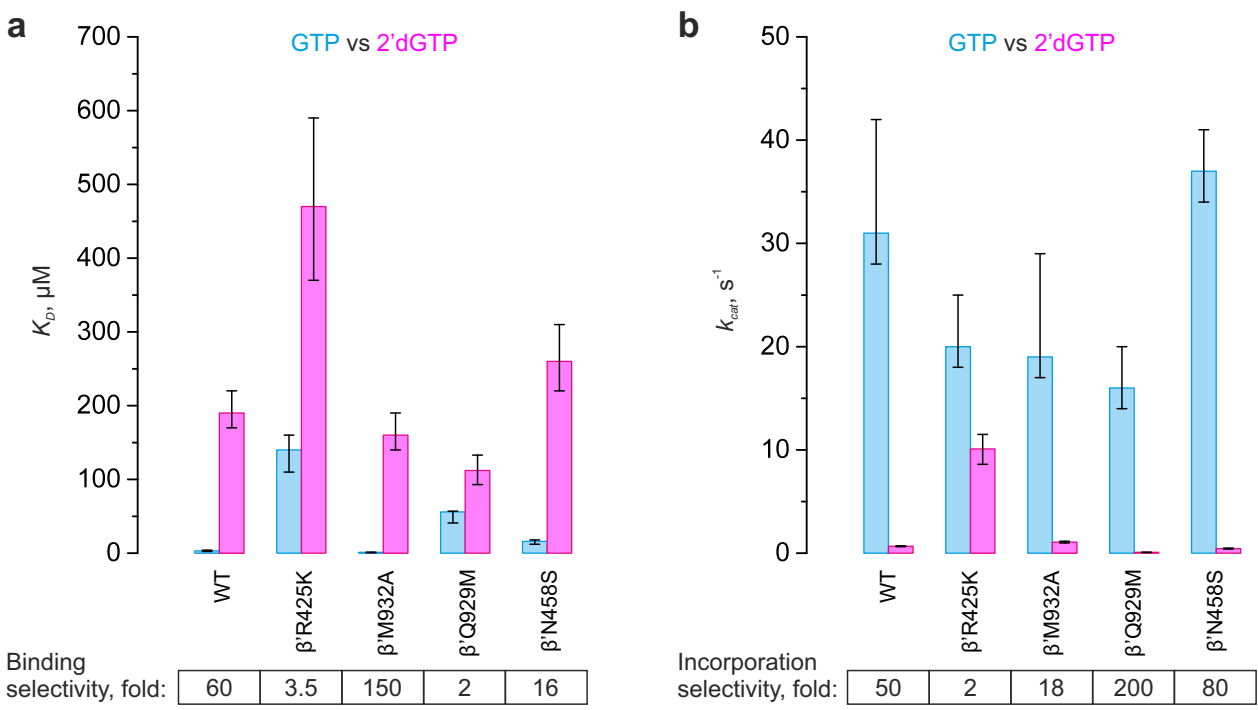

Fig. 3 Nucleo-sugar selectivities of the WT and variant E. coli RNAP. a Equilibrium dissociation constants for the reversible binding of GTP and 2'dGTP. b Turnover numbers for incorporation of GMP and 2'dGMP. Cyan (GTP) and magenta ( $2^{\prime} \mathrm{dGTP}$ ) bars indicate the best-fit values of the parameters estimated by the global fit of the data in Fig. 2b, c and Supplementary Figs. 1, 2 to model (1) (GTP) or equation (1) (2'dGTP). Duplicate data were combined for the analysis. Upper and lower bounds of the parameters values (error bars) were calculated by FitSpace routine of Kintek Explorer software (GTP) or Origin 2015 software ( $\left.2^{\prime} \mathrm{dGTP}\right)$ at 10\% increase in $\mathrm{Chi}^{2}$. Error bars define ranges of the parameters values that support a good fit of the model to data and are not measures of the biological variability. Numerical values of the parameters are indicated in Tables 1 and 2 and Supplementary Table 2.

Table 1 Kinetic parameters for the substrate utilization by E. coli RNAPs (fit to model 1).

\begin{tabular}{|c|c|c|c|c|c|c|c|}
\hline RNAP & Substrate & $k_{\mathrm{on},} \mu \mathrm{M}^{-1} \mathrm{~s}^{-1}$ & $k_{\text {off, }} s^{-1}$ & $k_{\text {cat },} s^{-1}$ (fast) & $k_{\text {cat },} \mathrm{s}^{-1}$ (slow) & Fast fraction, $\%$ & $K_{\mathrm{D},} \mu \mathrm{M}$ \\
\hline WT & GTP & $2.5(2.2-3.0)$ & $7.7(4.0-9.6)$ & $31(28-42)$ & $2.6(0.8-7.6)$ & $88(77-93)$ & $3.1(2.3-4.0)$ \\
\hline WT & 2'dGTP & $>0.24$ & $>45$ & $1.4(1.1-2.3)$ & $0.35(0.22-0.49)$ & $52(30-70)$ & $190(160-220)$ \\
\hline$\beta^{\prime} \mathrm{R} 425 \mathrm{~K}$ & GTP & $0.5(0.4-0.8)$ & $72(57-120)$ & $20(18-25)$ & $1.3(0.4-4.1)$ & $86(76-92)$ & $140(110-160)$ \\
\hline WT & 3'dGTP & $2.7(2.2-4.4)$ & $87(70-140)$ & $12(11-13)$ & $0.74(0.5-1.4)$ & $80(75-85)$ & $32(28-38)$ \\
\hline
\end{tabular}

Reaction products were modeled as sums of independent contributions by fast and slow fractions of RNAP; contributions of each fraction were modeled as model (1). Upper and lower bounds were calculated at a $10 \%$ increase in $\mathrm{Chi}^{2}$ by the FitSpace routine of KinTek Explorer software.

Table 2 Kinetic parameters for the 2'dGTP utilization by E. coli RNAPs (fit to equation 1).

\begin{tabular}{|c|c|c|c|c|c|}
\hline RNAP & $k, s^{-1}$ & $\beta$ (stretching parameter) & $K m, \mu M$ & Median reaction time, $s$ & Median reaction rate, $\mathrm{s}^{-1}$ \\
\hline WT & $0.62(0.58-0.65)$ & $0.83(0.80-0.85)$ & $190(170-220)$ & $1.04(0.98-1.11)$ & $0.67(0.62-0.71)$ \\
\hline$\beta^{\prime} \mathrm{R} 425 \mathrm{~K}$ & $9.7(8.4-11.3)$ & $0.90(0.84-0.96)$ & $470(370-590)$ & $0.069(0.059-0.079)$ & $10.1(8.6-11.5)$ \\
\hline$\beta^{\prime} \mathrm{M} 932 \mathrm{~A}$ & $1.01(0.94-1.09)$ & $0.85(0.81-0.89)$ & $160(140-190)$ & $0.64(0.59-0.69)$ & $1.07(0.99-1.15)$ \\
\hline$\beta^{\prime} \mathrm{N} 458 \mathrm{~S}$ & $0.42(0.39-0.45)$ & $0.83(0.80-0.87)$ & $260(220-310)$ & $1.5(1.4-1.7)$ & $0.45(0.41-0.49)$ \\
\hline
\end{tabular}

Upper and lower bounds were calculated at a 10\% increase in $\mathrm{Chi}^{2}$ by Origin 2015 software.

substrate and could be disregarded when comparing pre-G pauses that occurred upstream of all at- $\mathrm{C}$ and at-G pauses.

In contrast to the WT RNAP, the $\beta^{\prime} \mathrm{R} 425 \mathrm{~K}$ enzyme did not pause prior to the incorporation of the $2^{\prime} \mathrm{dGMP}$ (Fig. 4), consistently with the significantly higher $2^{\prime}$ dGMP incorporation rate observed in SNA assays (Fig. 3b). Moreover, the $\beta^{\prime}$ R425L RNAP also did not accumulate at the pre-G sites despite being strongly defective during processive transcription (Fig. 4a and Supplementary Fig. 3). These data suggest that the loss of selectivity is attributable to the absence of $\beta^{\prime} \mathrm{R} 425$ rather than the presence of the Lys residue at the corresponding position.
The $\beta^{\prime}$ M932A RNAP paused noticeably less whereas the $\beta^{\prime}$ Q929M RNAP paused noticeably more than the WT RNAP at the pre-G sites (Fig. 4a and Supplementary Fig. 3) consistently with the 2 -fold higher $\left(\beta^{\prime} \mathrm{M} 932 \mathrm{~A}\right)$ and 10 -fold lower $\left(\beta^{\prime} \mathrm{Q} 932 \mathrm{M}\right) k_{\text {cat }}$ for the 2 dGMP incorporation in the SNA experiments (Fig. $3 \mathrm{~b}$ and Table 2). In contrast, the $\beta^{\prime} \mathrm{N} 458 \mathrm{~S}$ RNAP was largely indistinguishable from the WT RNAP in its ability to utilize $2^{\prime}$ dGTP in the processive transcription assay (Fig. 4 and Supplementary Fig. 3), presumably because this assay is not sensitive enough to resolve the $\sim 1.5$-fold difference in $k_{\text {cat }}$ for the 2 'dGMP incorporation (Fig. $3 \mathrm{~b}$ and Table 2). Overall, the analysis of the $2^{\prime}$ dGTP utilization during processive transcription of 
a

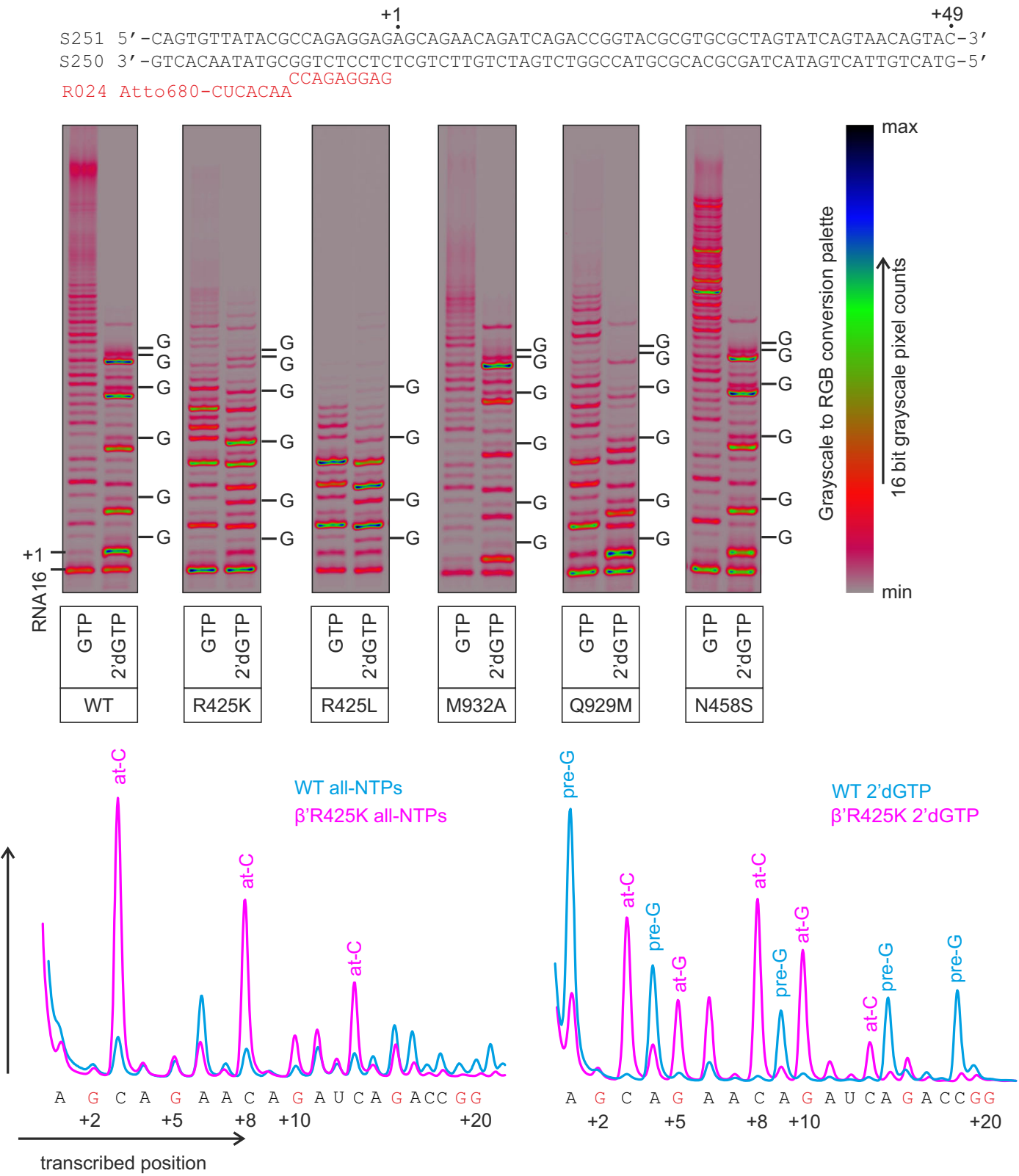

Fig. 4 Utilization of 2'dGTP during processive transcription by the WT and variant $\boldsymbol{E}$. coli RNAPs. a TECs were assembled using the scaffold shown above the gel panels and chased with $50 \mu \mathrm{M}$ ATP, CTP, UTP, and GTP or $2^{\prime} \mathrm{dGTP}$ for 2 min at $25^{\circ} \mathrm{C}$. The positions of GMPs in resolved stretches of the transcribed sequence are marked along the right edge of gel panels; 16-bit grayscale scans were normalized using max pixel counts within each gel panel and pseudo-colored using RGB palette. $\mathbf{b}$ Lane profiles of transcription in all-NTPs and 2'dGTP chases by the WT (cyan) and $\beta^{\prime}$ R425K (magenta) RNAPs quantified from gels in $\mathbf{a}$. Traces were manually aligned along the $X$-axis and scaled along the $Y$-axis using several sequence positions as references. All experiments were repeated in triplicate with similar results. Source data are provided as a Source Data file.

diverse sequences by the WT and variant RNAPs recapitulated the major effects observed in the SNA experiments.

Next, we tested the effects of the $\beta^{\prime} \mathrm{R} 425 \mathrm{~K}, \beta^{\prime} \mathrm{M} 932 \mathrm{~A}, \beta^{\prime} \mathrm{Q} 932 \mathrm{M}$, and $\beta^{\prime} \mathrm{N} 458 \mathrm{~S}$ substitutions on utilization of $2^{\prime} \mathrm{dATP}, 2^{\prime} \mathrm{dCTP}$, and $2^{\prime}$ dUTP (Supplementary Figs. 4-7). For each $2^{\prime}$ dNTP, we designed a template where the $2^{\prime} \mathrm{dNTP}$ is incorporated several times early in transcription, thereby allowing unambiguous interpretation of the accumulation of RNAPs at sites preceding the $2^{\prime} \mathrm{dNMP}$ incorporation. An analysis of the utilization of $2^{\prime}$ dATP, $2^{\prime}$ dCTP, and 2'dUTP largely recapitulated the effects observed for $2^{\prime} \mathrm{dGTP}$, except that $\beta^{\prime} \mathrm{N} 458 \mathrm{~S}$ was markedly inferior to the WT RNAP in utilizing $2^{\prime} \mathrm{dATP}$ and $2^{\prime} \mathrm{dUTP}$. Overall, these data demonstrated that the enhanced or diminished capabilities of the variant RNAPs to utilize $2^{\prime}$ dGTP in the SNA assays reflected, in qualitative terms, their capabilities to utilize all four 2 'dNTPs.

$\beta^{\prime}$ Arg425 favors the binding of $2^{\prime} \mathrm{dCTP}$ in the $2^{\prime}$-endo conformation. The role of $\beta^{\prime}$ Arg 425 in selectively promoting the binding of NTPs was easy to explain because $\beta^{\prime}$ Arg 425 interacts with the $2^{\prime} \mathrm{OH}$ of the NTP analogs in several RNAP structures (Supplementary Table 1 and Fig. 1d). In contrast, the observation that $\beta^{\prime}$ Arg 425 selectively inhibited the incorporation of $2^{\prime}$ dNTPs could not be readily explained: our results show that the $\beta^{\prime}$ Arg425 substitutions promote the incorporation of the substrate that lacks the $2^{\prime} \mathrm{OH}$ group, which $\beta^{\prime}$ Arg 425 would interact with. We hypothesized that, in the absence of the $2^{\prime} \mathrm{OH}, \beta^{\prime} \operatorname{Arg} 425$ 

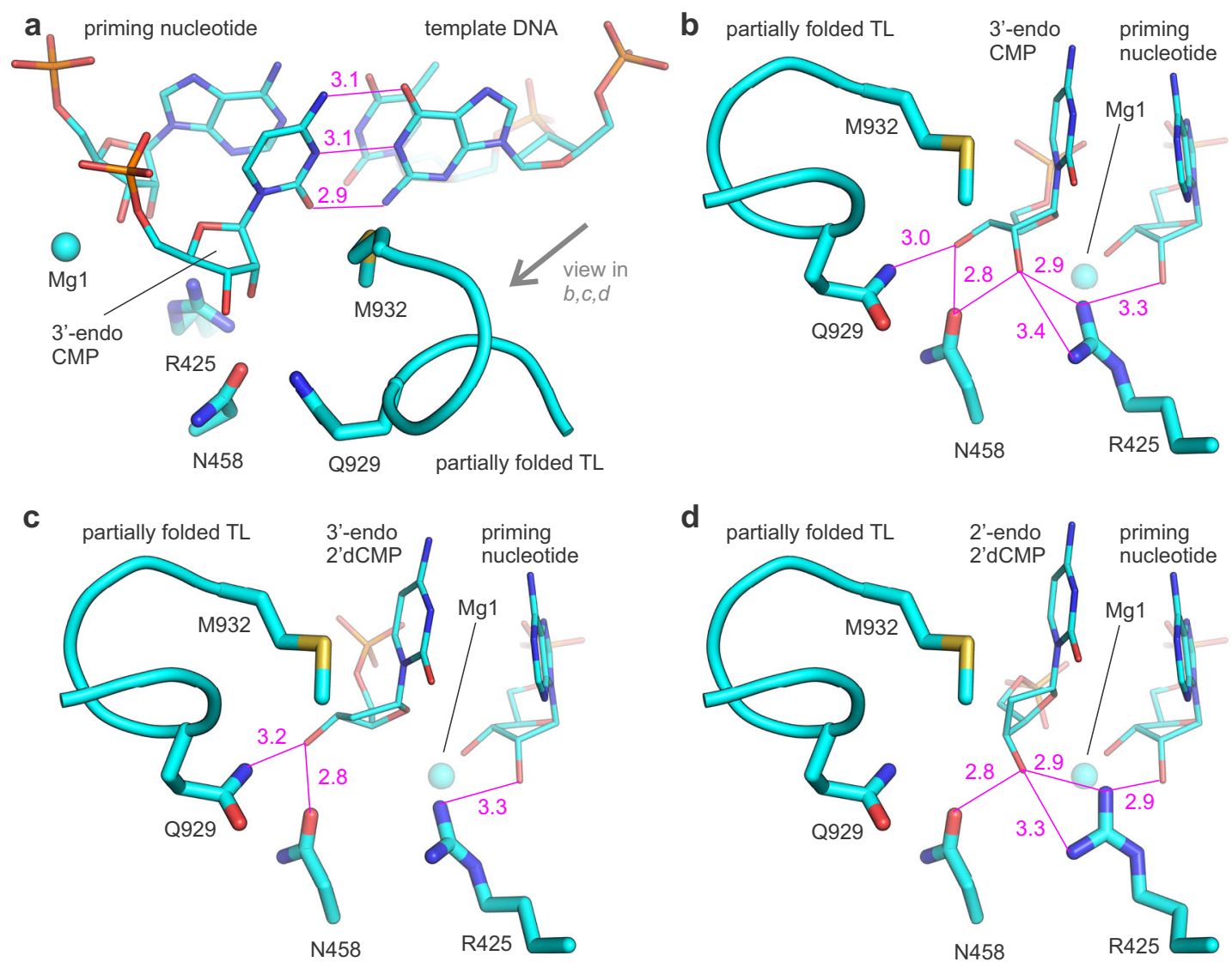

Fig. 5 Docking models of $\boldsymbol{T}$. thermophilus RNAP with ribo- and deoxyribonucleotides. In silico docking of the $3^{\prime}$-endo CMP (a, b), $3^{\prime}$-endo $2^{\prime}$ dCMP (c), and $2^{\prime}$-endo $2^{\prime} \mathrm{dCMP}$ (d) in the semi-closed active site of $T$. thermophilus RNAP. Magenta numbers are interatomic distances in $\AA$. Source data are provided as a Source Data file.

interacted with something else and that this interaction slowed down the incorporation of $2^{\prime} \mathrm{dNMPs}$ into the nascent RNA. We further reasoned that the $3^{\prime} \mathrm{OH}$ group of the $2^{\prime} \mathrm{dNTP}$ was the most likely interacting partner of $\beta^{\prime}$ Arg 425 , an inference supported by MD simulations of $S$. cerevisiae RNAP II (ref. ${ }^{27}$ ). However, the $3^{\prime} \mathrm{OH}$ group is positioned too far from $\beta^{\prime} \mathrm{Arg} 425$ when the sugar moiety is in the $3^{\prime}$-endo conformation (Supplementary Table 1). We further hypothesized that the $3^{\prime} \mathrm{OH}$ could move to within the hydrogen bond distance of $\beta^{\prime} \operatorname{Arg} 425$ if the deoxyribose moiety adopted a $2^{\prime}$-endo conformation.

To test this hypothesis in silico, we removed cytidine- $5^{\prime}-[(\alpha, \beta)$ methyleno]triphosphate (CMPCPP) from the structural model of the initiation complex of T. thermophilus RNAP (PDB ID 4Q4Z) ${ }^{18}$ and docked $2^{\prime}$-endo $2^{\prime} \mathrm{dCMP}, 3^{\prime}$-endo $2^{\prime} \mathrm{dCMP}$, and $3^{\prime}$-endo CMP (as a control) to the vacated active site (Fig. 5). We used nucleoside monophosphates instead of triphosphates as ligands because the docking software failed to correctly model interactions of triphosphate moieties with active site metal ions thereby complicating the interpretation of docking results (see "Methods"). The docking algorithm recovered high-scoring templated poses for CMP in 10 out of 10 runs, lower-scoring templated poses for $3^{\prime}$-endo $2^{\prime} \mathrm{dCMP}$ in 8 out of 10 runs and $2^{\prime}$-endo $2^{\prime}$ dCMP in 5 out of 10 runs (Supplementary Table 3). The $\beta^{\prime}$ Arg425 side chain was kept flexible in the latter case because our manual assessment suggested that a sub-angstrom repositioning of $\beta^{\prime}$ Arg 425 would be needed to accommodate the $2^{\prime}$-endo deoxyribose. We then fixed the $\beta^{\prime}$ Arg425 conformation observed in the highest-scoring templated pose and performed 10 additional docking runs. This time templated poses were recovered in 10 out of 10 runs. The robust recovery of templated poses suggested that the RNAP active site is well-suited for binding of the $2^{\prime}$-endo conformer of the $2^{\prime} \mathrm{dCMP}$ moiety via hydrogen bonding between the $3^{\prime} \mathrm{OH}$ and $\beta^{\prime} \mathrm{Arg} 425$ (Fig. 5d), lending credence to our hypothesis.

To further test our hypothesis in crystallo, we solved the X-ray crystal structure of the initially transcribing complexes containing T. thermophilus RNAP, DNA, and 3-nt RNA primer with incoming $2^{\prime} \mathrm{dCTP}$ bound at the active site at $3.14 \AA$ resolution. The structure displayed a well-resolved electron density of $2^{\prime}$ dCTP and $\beta^{\prime}$ Arg425 closely approaching the deoxyribose moiety (Figs. 6, 7, Table 3, and Supplementary Fig. 8a). 2'dCTP was observed in the pre-insertion conformation that was unsuitable for catalysis because the $\alpha$-phosphate was located $5.7 \AA$ from the $3^{\prime} \mathrm{OH}$ of the RNA primer. The electron density was consistent with the interaction between the $\beta^{\prime} A r g 425$ residue and the $3^{\prime} \mathrm{OH}$ group of the deoxyribose in the $2^{\prime}$-endo conformation. While the resolution of the structure was insufficient to unambiguously determine the conformation of the deoxyribose, the $3^{\prime} \mathrm{OH}$ of the $2^{\prime}$ endo conformer was positioned to hydrogen bond with up to three RNAP atoms (Fig. 6a), whereas the $3^{\prime} \mathrm{OH}$ of the $3^{\prime}$-endo conformer fitted into the omit map could only form a single hydrogen bond (Fig. 6b). Considering that $2^{\prime}$ dNTPs intrinsically prefer the $2^{\prime}$-endo conformation in solution and when bound to RNA template in a non-enzymatic system ${ }^{3}$, these observations suggest that $2^{\prime} \mathrm{dCTP}$ predominantly adopts the $2^{\prime}$-endo conformation upon binding to the open active site of RNAP (TL unfolded, see below). Indeed, the $2^{\prime}$-endo $2^{\prime} \mathrm{dCTP}$ is intrinsically more favorable than the $3^{\prime}$-endo conformer and can form more favorable interactions with the amino acid residues in the open active site. Interestingly, the density for the metal ion complexed by the $\beta$ - and $\gamma$-phosphates of $2^{\prime} \mathrm{dCTP}$ was weak and the 

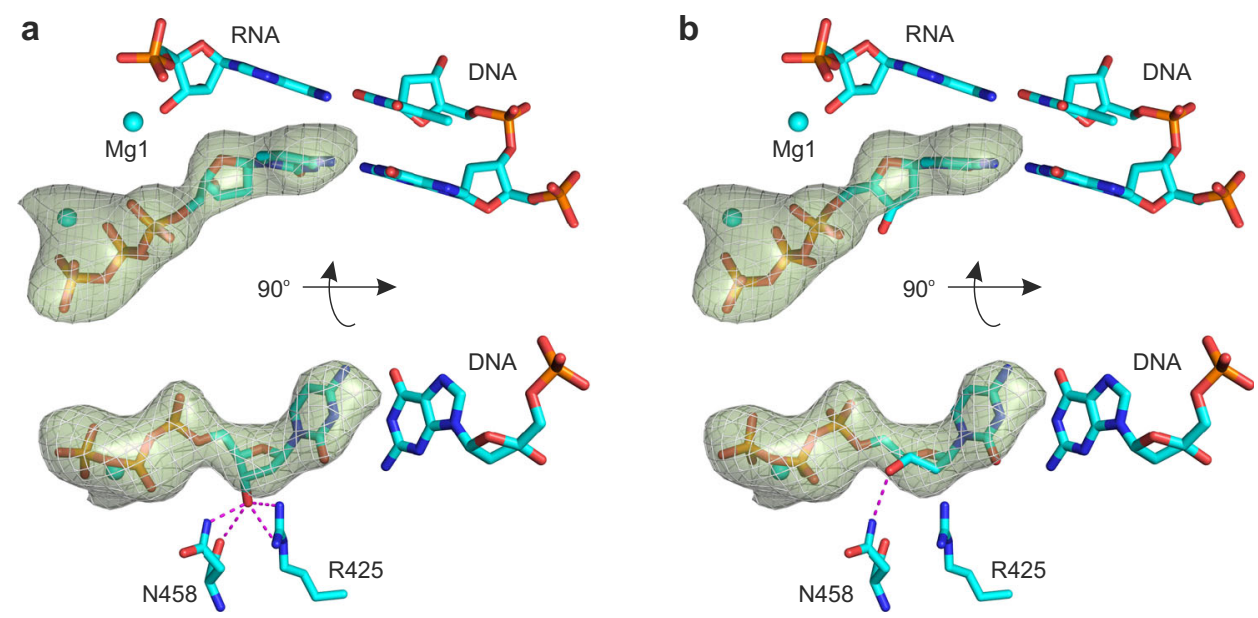

Fig. 6 The $\mathbf{2}^{\prime}$ - and $\mathbf{3}^{\prime}$-endo $\mathbf{2}^{\prime}$ dCTPs fitted into the omit map (36) of the RNAP-2'dCTP complex. a The $3^{\prime} \mathrm{OH}$ group of the $2^{\prime}$-endo conformer is positioned to form up to three hydrogen bonds and a polar interaction with RNAP atoms (magenta lines, interatomic distances $2.5-3.1 \AA$ ). b The $3^{\prime} \mathrm{OH}$ of the 3'-endo conformer can hydrogen bond with one RNAP atom. The 2'- and 3'-endo conformers were derived from PDB IDs $2 \mathrm{HVW}$ (resolution: $1.67 \AA$ ) and 4DQI (resolution: $1.69 \AA$ ), respectively, and fitted into the omit map by rotating bonds but preserving bond lengths and angles. Source data are provided as a Source Data file.
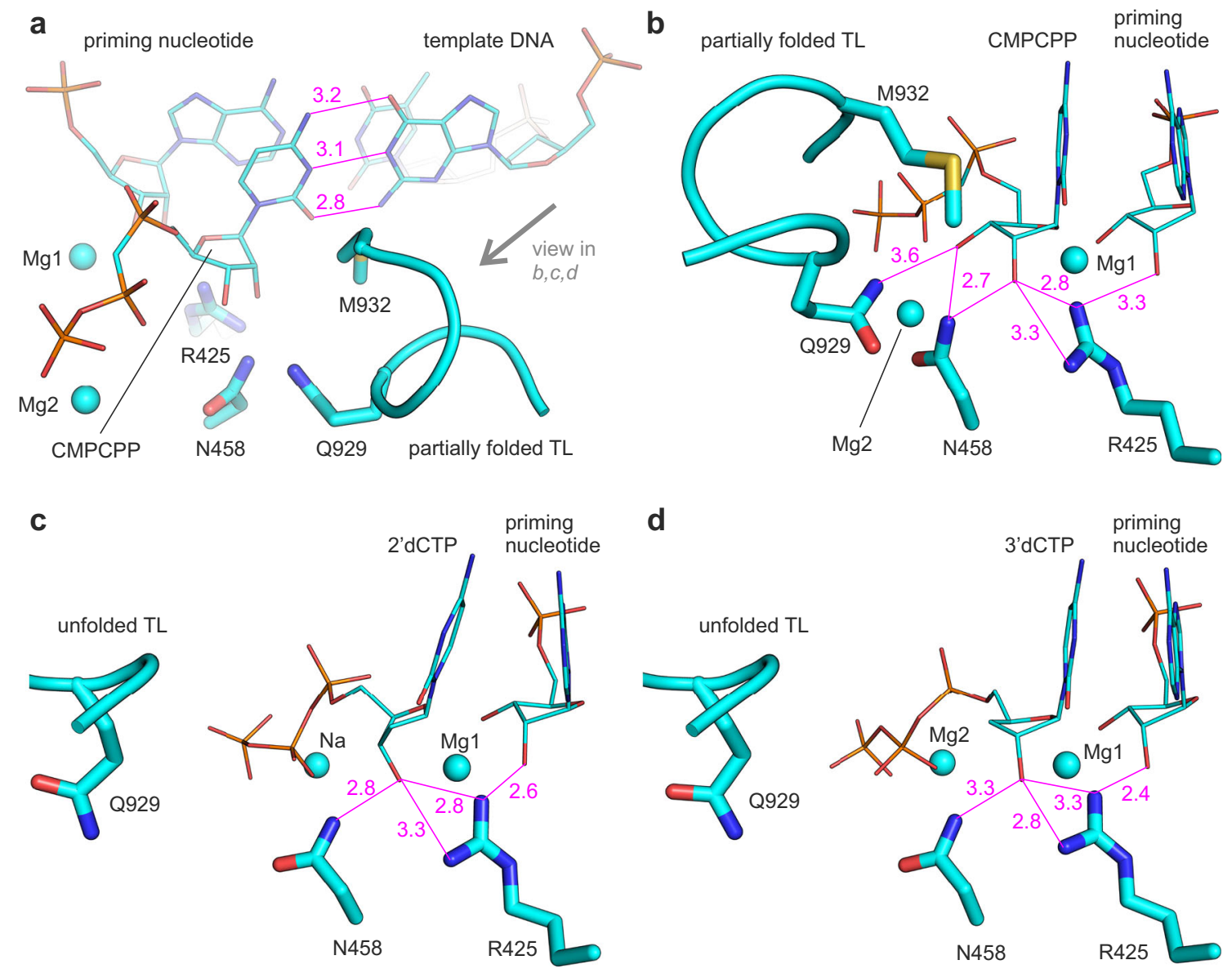

Fig. 7 X-ray crystal structures of $\boldsymbol{T}$. thermophilus RNAP with ribo- and deoxyribonucloside substrates. Crystallographically observed binding poses of $\operatorname{CMPCPP}(\mathbf{a}, \mathbf{b}), 2^{\prime} \mathrm{dCTP}(\mathbf{c})$, and 3'dCTP (d) in the active site of T. thermophilus RNAP. Magenta numbers are interatomic distances in $\AA$. Panels a and $\mathbf{b}$ were prepared using PDB ID 4Q4Z ${ }^{18}$. Pre-catalytic complexes in $\mathbf{c}$ and $\mathbf{d}$ were trapped due to the low reactivity of deoxyribonucleoside substrates and the slow catalysis by RNAP in crystallo 52 . Source data are provided as a Source Data file.

coordination distances were longer than typically observed for $\mathrm{Mg}^{2+}$ in the corresponding position. We modeled this metal ion as $\mathrm{Na}^{+}$rather than $\mathrm{Mg}^{2+}$ similarly to what has been proposed for DNA polymerase $\beta^{32}$.
The TL was completely unfolded in the structure of the initially transcribing complex with $2^{\prime} \mathrm{dCTP}$, in contrast to a partially helical conformation typically observed in the structures of RNAP complexes with non-hydrolysable NTP analogs (Supplementary 
Table 3 Data collection and refinement statistics.

\begin{tabular}{|c|c|c|}
\hline $\begin{array}{l}\text { Complex } \\
\text { PDB code }\end{array}$ & $\begin{array}{l}\text { 2'dCTP } \\
6 W O X\end{array}$ & $\begin{array}{l}\text { 3'dCTP } \\
6 \text { WOY }\end{array}$ \\
\hline \multicolumn{3}{|l|}{ Data collection } \\
\hline Space group & $\mathrm{C} 2$ & $\mathrm{C} 2$ \\
\hline \multicolumn{3}{|l|}{ Cell dimensions } \\
\hline$a(\AA)$ & 185.44 & 185.98 \\
\hline$b(\AA)$ & 102.65 & 102.47 \\
\hline$c(\AA)$ & 295.38 & 296.04 \\
\hline$\beta\left(^{\circ}\right)$ & 98.91 & 98.87 \\
\hline Resolution $(\AA)$ & $30-3.14$ & $30-3.00$ \\
\hline Total reflections & 275,994 & 361,353 \\
\hline Unique reflections & 89,931 & 106,804 \\
\hline Redundancy & $3.1(2.5)$ & $3.4(2.9)$ \\
\hline Completeness (\%) & $94.3(68.6)$ & $96.9(73.6)$ \\
\hline $1 / \sigma$ & $10.06(1.44)$ & $14.78(1.73)$ \\
\hline$R_{\text {merge }}$ & $0.129(0.521)$ & $0.086(0.553)$ \\
\hline $\mathrm{CC}^{1 / 2}$ & $0.985(0.829)$ & $0.991(0.855)$ \\
\hline \multicolumn{3}{|l|}{ Refinement } \\
\hline Resolution $(\AA)$ & $30-3.14$ & $30-3.00$ \\
\hline$R_{\text {work }}$ & 0.196 & 0.206 \\
\hline$R_{\text {free }}$ & 0.261 & 0.219 \\
\hline No. of atoms & 28,569 & 28,569 \\
\hline \multicolumn{3}{|l|}{ R.m.s. deviations } \\
\hline Bond length $(\AA)$ & 0.010 & 0.009 \\
\hline Bond angles $\left({ }^{\circ}\right)$ & 1.22 & 1.12 \\
\hline Clashscore & 15.04 & 13.19 \\
\hline Ramachandran favored, \% & 85.68 & 86.95 \\
\hline Ramachandran outliers, \% & 0.37 & 0.37 \\
\hline
\end{tabular}

Table 1$)^{17-20}$. The destabilization of the TL folding could be due to the absence of interactions between the TL $\beta^{\prime}$ Gln929 and the $3^{\prime}$ $\mathrm{OH}$ of $2^{\prime} \mathrm{dCTP}$, that in turn is an expected consequence of the $2^{\prime}$ dCTP binding in the $2^{\prime}$-endo conformation (Fig. $5 \mathrm{~d}$ ). To test if the unavailability of the $3^{\prime} \mathrm{OH}$ group was indeed responsible for the destabilization of the TL folding, we solved the X-ray crystal structure of the initially transcribing complex of the $T$. thermophilus RNAP with $3^{\prime} \mathrm{dCTP}$ at $3.0 \AA$ resolution. The structure displayed a well-resolved density of $3^{\prime} \mathrm{dCTP}$ and $\beta^{\prime}$ Arg425 closely approaching the $3^{\prime}$-deoxyribose moiety (Fig. $7 \mathrm{~d}$ and Supplementary Fig. 8b). $3^{\prime} \mathrm{dCTP}$ was in the pre-insertion conformation unsuitable for catalysis because the a-phosphate was located $5.6 \AA$ away from the $3^{\prime} \mathrm{OH}$ of the RNA primer. The overall pose of $3^{\prime} \mathrm{dCTP}$ was similar to that of CMPCPP: the $3^{\prime}$ deoxyribose likely adopted a $3^{\prime}$-endo conformation and the $2^{\prime} \mathrm{OH}$ group interacted with $\beta^{\prime} A r g 425$. However, the TL was completely unfolded, supporting our hypothesis that the unavailability of the $3^{\prime} \mathrm{OH}$ group was alone sufficient to significantly destabilize the folding of the first helical turn of the TL.

Overall, the comparative analysis of RNAP structures with CMPCPP, $2^{\prime} \mathrm{dCTP}$, and $3^{\prime} \mathrm{dCTP}$ in combination with in silico docking experiments suggested that $\beta^{\prime}$ Arg425 inhibited the incorporation of $2^{\prime} \mathrm{dNTPs}$ by interacting with their $3^{\prime} \mathrm{OH}$ group and favoring the $2^{\prime}$-endo conformation of the deoxyribose moiety. At the same time, the structures did not provide a decisive answer as to why the $2^{\prime}$-endo conformations of $2^{\prime} \mathrm{dNTPs}$ were less suitable for incorporation into RNA than the $3^{\prime}$-endo conformations.

The misplacement of the $3^{\prime} \mathrm{OH}$ only partially accounts for the inertness of $\mathbf{2}^{\prime} \mathbf{d N T P s}$. The X-ray structures and in silico modeling experiments suggested that interactions between the $3^{\prime}$ $\mathrm{OH}$ of the deoxyribose moiety and the $\beta^{\prime} \mathrm{Arg} 425$ or $\beta^{\prime} \mathrm{Gln} 929$ residues were mutually exclusive. Accordingly, $\beta^{\prime}$ Arg425 could inhibit the incorporation of the $2^{\prime}$ dNMP solely by slowing down the initial steps of the TL folding, by sequestering the $3^{\prime} \mathrm{OH}$ group and preventing its interaction with the TL $\beta^{\prime} \mathrm{Gln} 929$. To test this hypothesis, we determined the incorporation rate of $3^{\prime} \mathrm{dGMP}$ by the WT RNAP (Supplementary Fig. 2c). We found that the $k_{\text {cat }}$ for $3^{\prime}$ dGMP incorporation was only 5 -fold slower than the $k_{\text {cat }}$ for GMP incorporation and 10-fold higher than the $k_{\text {cat }}$ for $2^{\prime}$ dGMP incorporation (Table 1). These data demonstrated that the sequestration of the $3^{\prime} \mathrm{OH}$ group accounted for no more than a 5fold inhibition of the $2^{\prime} \mathrm{dGMP}$ incorporation by $\beta^{\prime} \mathrm{Arg} 425$. The remaining 10 -fold inhibition of the overall 50 -fold inhibitory effect was contributed by some other features of the $2^{\prime}$-endo binding pose, as discussed below.

\section{Discussion}

In this study, we performed a systematic analysis of the contributions of the active site residues of the multi-subunit RNAP to selecting NTPs over $2^{\prime}$ dNTPs. We identified a conserved Arg residue, $\beta^{\prime}$ Arg425 (E. coli RNAP numbering) as the major determinant of the sugar selectivity. The $\beta^{\prime} \operatorname{Arg} 425$ residue favored binding of GTP over $2^{\prime} \mathrm{dGTP}$ and selectively inhibited the incorporation of $2^{\prime} \mathrm{dNMPs}$ into RNA (Figs. 3, 4 and Table 1).

The enhancement of NTP binding by $\beta^{\prime} A r g 425$ is consistent with the observation that $\beta^{\prime} A r g 425$ is positioned to hydrogen bond with the $2^{\prime} \mathrm{OH}$ of the NTP substrate analogs in several RNAP structures (Supplementary Table 1) and with MD simulations of the S. cerevisiae RNAP II (ref. ${ }^{27}$ ). However, the existing data fail to explain the inhibition of the $2^{\prime} \mathrm{dNTP}$ incorporation by $\beta^{\prime}$ Arg425. In search of an explanation, we performed in silico docking experiments and solved the X-ray crystal structures of transcribing T. thermophilus RNAP with the cognate $2^{\prime} \mathrm{dCTP}$ and $3^{\prime} \mathrm{dCTP}$. These experiments revealed that $\beta^{\prime} \mathrm{Arg} 425$ interacts with the $3^{\prime} \mathrm{OH}$ group of the $2^{\prime} \mathrm{dNTP}$ substrate and favors the $2^{\prime}$-endo conformation of the deoxyribose (Figs. 5d, 6a, and 7c). In contrast, the ribose of the cognate NTP substrate is stabilized in the $3^{\prime}$-endo conformation by multiple polar contacts and hydrogen bonds with $\beta^{\prime}$ Arg425, $\beta^{\prime}$ Asn458, and $\beta^{\prime}$ Gln929 (Figs. 1d, 5b, and 7b).

A comparison of the RNAP structures with bound CMPCPP, $2^{\prime} \mathrm{dCTP}$, and $3^{\prime} \mathrm{dCTP}$ revealed very small changes in the $\beta^{\prime} \mathrm{Arg} 425$ conformation (Supplementary Fig. 8c), arguing against a scenario where the repositioning of the $\beta^{\prime}$ Arg 425 side chain upon the binding of $2^{\prime} \mathrm{dNTPs}$ slows the catalysis of the phosphodiester bond formation ${ }^{27}$. Accordingly, we reasoned that the preferential selection of the catalytically inert $2^{\prime}$-endo conformers of $2^{\prime} \mathrm{dNTPs}$ and the deformation of the catalytically labile $3^{\prime}$-endo conformers of $2^{\prime} \mathrm{dNTPs}$ by $\beta^{\prime} \mathrm{Arg} 425$ were likely the major factors behind the slow incorporation of $2^{\prime} \mathrm{dNMPs}$. However, it remained unclear why the $2^{\prime}$-endo conformers of the substrates were less suitable for the incorporation than the $3^{\prime}$-endo conformers.

We first explored the possibility that the sequestration of the $3^{\prime}$ $\mathrm{OH}$ group by $\beta^{\prime} \mathrm{Arg} 425$ makes it unavailable for the interaction with $\beta^{\prime}$ Gln929 of the TL (Figs. $5 \mathrm{~d}$ and $7 \mathrm{c}$ ), thereby destabilizing the TL-mediated closure of the active site. Indeed, the TL is partially folded in most structures with ribonucleotide substrate analogs (Fig. 5b, Supplementary Table 1$)^{17-20}$, yet was completely unfolded in the structures we obtained with either $2^{\prime}$ dCTP (Fig. 5c) or $3^{\prime} \mathrm{dCTP}$ (Fig. 5d). However, we found that the rate of the $3^{\prime}$ dGMP incorporation by E. coli RNAP was 10 -fold faster than the rate of the $2^{\prime} \mathrm{dGMP}$ incorporation (Table 1 ). Notably, the T. thermophilus RNAP also incorporates $3^{\prime} \mathrm{dNMPs}$ faster than $2^{\prime}$ $\mathrm{dNMPs}^{22}$. These results suggested that the sequestration of the $3^{\prime}$ 
OH group by $\beta^{\prime} A r g 425$ could account for no more than a 5 -fold out of its 50 -fold overall inhibitory effect.

Similarly, the effects of the $\beta^{\prime} \mathrm{Q} 929 \mathrm{M}$ substitution were inconsistent with the idea that the $3^{\prime} \mathrm{OH}$ capture by $\beta^{\prime} \mathrm{Arg} 425$ could alone account for the slow rate of the 2 'dNMP incorporation. If that were true, the $\beta^{\prime} \mathrm{Q} 929 \mathrm{M}$ variant should be relatively insensitive to the absence of the $2^{\prime} \mathrm{OH}$ group. However, the opposite was true: $\beta^{\prime} \mathrm{Q} 929 \mathrm{M}$ was only 2 -fold slower in incorporating GMP than the WT RNAP, but 10-fold slower in incorporating $2^{\prime} \mathrm{dGMP}$. We propose that $\beta^{\prime} \mathrm{Gln} 929$ competes with $\beta^{\prime} A r g 425$ for the $3^{\prime} \mathrm{OH}$ group of the $2^{\prime} \mathrm{dNTP}$ substrate: $\beta^{\prime} \operatorname{Arg} 425$ favors the catalytically inert $2^{\prime}$-endo conformer (Figs. $5 \mathrm{~d}, 6 \mathrm{a}$, and $7 \mathrm{c}$ ), whereas $\beta^{\prime} \mathrm{Gln} 929$ favors the catalytically labile $3^{\prime}$-endo conformer (Fig. 5 c). As a result, $\beta^{\prime} G \ln 929$ is more important during the incorporation of $2^{\prime} \mathrm{dNMPs}$ than NMPs.

Since the TL folding can account only for a fraction of the inhibitory effect, what other factors make the 2 '-endo conformers of $2^{\prime}$ dNTPs catalytically inert? It is noteworthy that the sugars of the attacking and substrate nucleotides adopt the $3^{\prime}$-endo conformation in all RNAPs and DNAPs during the nucleotide incorporation ${ }^{4}$. In other words, even the $3^{\prime}$ ends of DNA primers adopt the $3^{\prime}$-endo conformation to catalyze the incorporation of the $2^{\prime} \mathrm{dNMPs}$ into the DNA. Apparently, the A-form geometry is much better suited for the catalysis of the nucleotide condensation than the B-form geometry ${ }^{3,33}$. The better accessibility of the nucleophilic $3^{\prime} \mathrm{OH}$ group of the attacking nucleotide is likely the primary reason. The substrate then adopts the $3^{\prime}$-endo conformation to match the overall geometry of the A-form duplex and to avoid clashes with the attacking nucleotide ${ }^{4}$.

In general terms, the inertness of the $2^{\prime}$-endo conformation of $2^{\prime}$ dNTPs can be partially attributed to the differences in the conformations of the triphosphate moieties that in turn originate from the differences in the bond angles at $\mathrm{C}^{\prime}$ of the sugar between the $3^{\prime}$ - and $2^{\prime}$-endo conformers (Fig. 1b). We term this inhibitory component as $\mathrm{C}^{\prime}$-geometry-dependent effects. However, it is impossible to further refine this hypothesis at present because the superimposition of different structures suggests a considerable conformational diversity of triphosphate moieties in the RNAP active site (Fig. 4 in ref. ${ }^{16}$ ). High-resolution and timeresolved structural studies of nucleotide incorporation by the multi-subunit RNAPs would be necessary to determine the reasons behind the inertness of the $2^{\prime}$-endo conformers of $2^{\prime} \mathrm{dNTPs}$.

Noteworthy, the conserved Arg is one of only seven catalytic residues that are conserved in the superfamily of "two- $\beta$-barrel" RNAPs $^{34,35}$ that includes the multi-subunit RNAPs and very distantly related cellular RNA-dependent RNAPs (RdRps) involved in the RNA interference (Supplementary Fig. 9). Accordingly, the common ancestor of the two- $\beta$-barrel RNAPs could conceivably discriminate against $2^{\prime} \mathrm{dNTPs}$ and therefore likely evolved in the presence of both NTPs and $2^{\prime} \mathrm{dNTPs}$. This inference lends credence to the hypothesis that proteins evolved in primordial lifeforms that already possessed both RNA and DNA $^{36,37}$.

Viral RdRps (members of the "right-hand" superfamily of nucleic acid polymerases) are not homologous to multi-subunit RNAPs but share some elements of their sugar selection strategies. It appears that the $3^{\prime} \mathrm{OH}$ of the substrate NTP facilitates the active site closure in both classes of enzymes. In multi-subunit RNAPs, $3^{\prime} \mathrm{OH}$ facilitates the TL folding via the interaction with $\beta^{\prime}$ Gln929 (ref. ${ }^{18}$ ), whereas in viral RdRps, $3^{\prime} \mathrm{OH}$ initiates the closure by sterically clashing with Asp238 (poliovirus RdRp numbering ${ }^{38}$. In both classes of enzymes, $2^{\prime}$ dNTPs adopt a $2^{\prime}$-endo pose wherein the $3^{\prime} \mathrm{OH}$ is misplaced and cannot readily facilitate the closure of the active site, explaining low reactivities of $2^{\prime}$ dNTPs. However, $3^{\prime}$ dNTPs are better substrates than $2^{\prime}$ dNTPs also for viral RdRps ${ }^{30}$ suggesting that the low reactivity of the $2^{\prime}$ - endo $2^{\prime}$ dNTPs additionally relies on C4'-geometry-dependent effects (see above), which lead to a suboptimal conformation of the triphosphate moiety, a suboptimal geometry of the transition state, or both.

Multi-subunit RNAPs and viral RdRps converged on using the $2^{\prime}$-endo binding pose to discriminate against $2^{\prime} \mathrm{dNTPs}$. In doing so these enzymes accentuate the intrinsic preferences of $2^{\prime}$ dNTPs to retain the inert $2^{\prime}$-endo conformation upon binding to the Aform template in the non-enzymatic system ${ }^{3}$. However, the exact implementations of the selection mechanisms are distinct. In multi-subunit RNAPs, the $2^{\prime}$-endo pose is stabilized by the $3^{\prime} \mathrm{OH} /$ $\beta^{\prime} A r g 425$ attraction, whereas in viral RdRps, the $2^{\prime}$-endo pose is imposed by the $3^{\prime} \mathrm{OH} / \mathrm{Asp} 238$ steric clash ${ }^{38}$. Multi-subunit RNAPs employ the conformational selection and preferentially sample the catalytically labile $3^{\prime}$-endo conformers of NTP and the catalytically inert $2^{\prime}$-endo conformers of $2^{\prime}$ dNTPs. In contrast, viral RdRps likely rely exclusively on the induced $\mathrm{fit}^{30}$ and bind the catalytically inert $2^{\prime}$-endo conformers of either NTPs or $2^{\prime}$ dNTPs. Following the initial binding, only NTPs can efficiently isomerize into catalytically labile $3^{\prime}$-endo conformers, ultimately repositioning the Asp238 and switching the RdRp active site on ${ }^{38}$. These principal differences in the substrate selection mechanisms can be potentially exploited for the concept-based design of sugar-modified substrate analog inhibitors of viral RdRps such as Remdesivir, one of few drugs currently available for COVID-19 treatment 39,40 .

In summary, our data show that the universally conserved Arg residue plays a central role in selecting NTPs over $2^{\prime}$ dNTPs by the multi-subunit RNAPs. When NTP binds in the RNAP active site, its ribose adopts the $3^{\prime}$-endo conformation that positions the $3^{\prime}$ $\mathrm{OH}$ group to interact with the universally conserved Gln residue of the TL domain and promotes the closure of the active site, whereas the triphosphate moiety can undergo rapid isomerization into the insertion conformation leading to efficient catalysis. The interaction of the conserved Arg residue with the $2^{\prime} \mathrm{OH}$ of the NTPs selectively enhances their binding more than 100 -fold and renders RNAP saturated with NTPs in the physiological concentration range. In contrast, the interaction of the conserved Arg with the $3^{\prime} \mathrm{OH}$ of the $2^{\prime} \mathrm{dNTP}$ substrates shapes their deoxyribose moiety into the catalytically inert $2^{\prime}$-endo conformation where the $3^{\prime} \mathrm{OH}$ cannot promote closure of the active site and substrate incorporation is additionally inhibited by the unfavorable geometry of the triphosphate moiety. The deformative action of the conserved Arg on the 2'dNTP substrates is an elegant example of active selection against a substrate that is a substructure of the correct substrate.

\section{Methods}

Reagents and oligonucleotides. DNA and RNA oligonucleotides were purchased from Eurofins Genomics GmbH (Ebersberg, Germany) and IBA Biotech (Göttingen, Germany). DNA oligonucleotides and RNA primers are listed in Supplementary Table 4 . NTPs, $2^{\prime} \mathrm{dATP}, 3^{\prime} \mathrm{dGTP}$, and CMPCPP were from Jena Bioscience (Jena, Germany); $2^{\prime} \mathrm{dGTP}, 2^{\prime} \mathrm{dUTP}$, and $2^{\prime} \mathrm{dCTP}$ were from Bioline Reagents (London, UK). TECs extended with $3^{\prime}$ dGMP did not extend further upon the addition of the next substrate NTP suggesting that $3^{\prime}$ dGTP stocks were free of GTP. TECs extended with $2^{\prime} \mathrm{dGMP}, 2^{\prime} \mathrm{dATP}$, and $2^{\prime} \mathrm{dUTP}$ migrated faster in the denaturing PAGE than TECs extended with the corresponding NMPs suggesting that $2^{\prime} \mathrm{dGTP}, 2^{\prime} \mathrm{dATP}$, and $2^{\prime} \mathrm{dUTP}$ stocks were free of the corresponding NTPs. $2^{\prime}$ dCTP stocks were slightly contaminated by CTP as evident from the WT and $\beta^{\prime}$ M932A RNAPs gels in Supplementary Fig. 6. These low $K_{\mathrm{D}}$ RNAPs scavenged and depleted the trace amounts of CTP when transcribing the first CMP encoding position but incorporate exclusively $2^{\prime} \mathrm{dCMP}$ when transcribing CMP encoding positions further downstream. While it was possible to deplete the contaminating CTP by pre-treatment with the unlabeled TEC, we opted to present the experiment with a slightly contaminated $2^{\prime} \mathrm{dCTP}$ as a showcase of our capabilities to detect contaminations of $2^{\prime} \mathrm{dNTPs}$ with NTPs.

Proteins. E. coli RNAPs were expressed in the E. coli strain T7 Express lysY/Iq (New England Biolabs, Ipswich, MA, USA) and purified by Ni-, heparin, and 
Q-sepharose chromatography as described previously ${ }^{41}$. RNAPs were dialyzed against storage buffer (50\% glycerol, $20 \mathrm{mM}$ Tris- $\mathrm{HCl} \mathrm{pH} 7.9,150 \mathrm{mM} \mathrm{NaCl}, 0.1$ mM EDTA, $0.1 \mathrm{mM} \mathrm{DTT}$ ) and stored at $-20^{\circ} \mathrm{C}$. Plasmids used for protein expression are listed in Supplementary Table 5. T. thermophilus RNAP holoenzyme was prepared as described previously ${ }^{18}$.

TEC assembly. TECs were assembled by a procedure developed by Komissarova et al. ${ }^{42}$. An RNA primer was annealed to the template DNA, and incubated with $1.5 \mu \mathrm{M}$ RNAP for $10 \mathrm{~min}$ at $25^{\circ} \mathrm{C}$ in TB10 buffer $\left(10 \mathrm{mM} \mathrm{MgCl}_{2}, 40 \mathrm{mM}\right.$ HEPES$\mathrm{KOH} \mathrm{pH} \mathrm{7.5,} 80 \mathrm{mM} \mathrm{KCl}, 5 \%$ glycerol, $0.1 \mathrm{mM}$ EDTA, and $0.1 \mathrm{mM}$ DTT) and with $2 \mu \mathrm{M}$ of the non-template DNA for $20 \mathrm{~min}$ at $25^{\circ} \mathrm{C}$. For TECs used in nucleotide addition measurements, RNA was the limiting component at $1 \mu \mathrm{M}$ (final concentration), and the template strand was used at $1.4 \mu \mathrm{M}$, whereas for TECs used in the translocation assay the template strand was limiting at $1 \mu \mathrm{M}$, and RNA was added at $1.4 \mu \mathrm{M}$.

In vitro transcription reactions, processive transcript elongation. The transcription reactions were initiated by the addition of $10 \mu$ lof the assembled TEC $(0.45 \mu \mathrm{M})$ to $10 \mu \mathrm{l}$ of the substrate mixture $\left(100 \mu \mathrm{M}\right.$ of each NTP or $\left.2^{\prime} \mathrm{dNTP}\right)$, both solutions were prepared in TB10 buffer. In total, five mixtures containing NTPs and $2^{\prime} \mathrm{dNTPs}$ in different combinations were employed. Four chase mixtures contained three NTPs and one $2^{\prime} \mathrm{dNTP}\left(2^{\prime} \mathrm{dATP}-, 2^{\prime} \mathrm{dCTP}-, \mathrm{d}^{\prime} \mathrm{GTP}-\right.$, and $2^{\prime} \mathrm{dUTP}-$ chase) whereas the control chase mixture contained four NTPs. The final concentration of NTPs and $2^{\prime}$ dNTPs in the reaction mixtures was $50 \mu \mathrm{M}$ each. The reactions were incubated for $2 \mathrm{~min}$ at $25^{\circ} \mathrm{C}$ and quenched with $40 \mu \mathrm{l}$ of Gel Loading Buffer ( $94 \%$ formamide, $20 \mathrm{mM} \mathrm{Li}_{4}$-EDTA, and $0.2 \%$ Orange G). RNAs were separated on $16 \%$ denaturing polyacrylamide gels and visualized with an Odyssey Infrared Imager (Li-Cor Biosciences, Lincoln, NE, USA); band intensities were quantified using the ImageJ software ${ }^{43}$.

Time-resolved nucleotide addition measurements. Time-resolved measurements of nucleotide addition were performed in an RQF 3 quench-flow instrument (KinTek Corporation, Austin, TX). The reaction was initiated by the rapid mixing of $14 \mu \mathrm{l}$ of $0.2 \mu \mathrm{M}$ TEC with $14 \mu \mathrm{l}$ of GTP $(400,2000$, or $4000 \mu \mathrm{M})$ or $2^{\prime} \mathrm{dGTP}(400$, 2000 , or $4000 \mu \mathrm{M})$ or $3^{\prime} \mathrm{dGTP}(5,20,50,200,1000 \mu \mathrm{M})$. Both TEC and substrate solutions were prepared in TB10 buffer. The reaction was allowed to proceed for $0.004-300 \mathrm{~s}$ at $25^{\circ} \mathrm{C}$ and quenched by the addition of $86 \mu \mathrm{l}$ of $0.45 \mathrm{M}$ EDTA or 0.5 $\mathrm{M} \mathrm{HCl}$. EDTA quenched reactions were mixed with $171 \mu \mathrm{l}$ of Gel Loading Buffer. $\mathrm{HCl}$ quenched reactions were immediately neutralized by adding $171 \mu \mathrm{l}$ of Neutralizing-Loading Buffer ( $94 \%$ formamide, $290 \mathrm{mM}$ Tris base, $13 \mathrm{mM}$ $\mathrm{Li}_{4} \mathrm{EDTA}, 0.2 \%$ Orange G). RNAs were separated on $16 \%$ denaturing polyacrylamide gels and visualized with an Odyssey Infrared Imager (Li-Cor Biosciences, Lincoln, NE, USA); band intensities were quantified using the ImageJ software ${ }^{43}$.

Time-resolved fluorescence measurements. Measurements were performed in an Applied Photophysics (Leatherhead, UK) SX.18MV stopped-flow instrument at $25^{\circ} \mathrm{C}$. The 6-MI fluorophore was excited at $340 \mathrm{~nm}$ and the emitted light was collected through a 400-nm longpass filter. The nucleotide addition reactions were initiated by mixing $60 \mu \mathrm{l}$ of $0.2 \mu \mathrm{M}$ TEC in TB10 buffer with $60 \mu \mathrm{l}$ of GTP (5-4000 $\mu \mathrm{M})$ or $2^{\prime}$ dGTP $(100-4000 \mu \mathrm{M})$ in TB10 buffer. At least three individual traces were averaged for each concentration of the substrate.

Data analyses. Time-resolved GMP incorporation data ( $\mathrm{HCl}$ and EDTA quenched reactions) and the translocation timetraces were simultaneously fitted to a three-step model (model 1) using the numerical integration capabilities of the KinTek Explorer software ${ }^{44}$ (KinTek Corporation, Austin, TX) largely as described previously ${ }^{45}$. The model postulated that the initial TEC16 reversibly binds the GTP substrate, undergoes the irreversible transition to TEC17 upon incorporation of the nucleotide into RNA, followed by the irreversible translocation. The EDTA quenched reactions were modeled using the pulse-chase routine of the Kin-Tek Explorer software. Time-resolved 2'dGMP incorporation concentration series (translocation timetraces) were globally fitted to a stretched exponential function (equation 1) using Origin 2015 software (OriginLab, Northampton, MA, USA): the exponent followed a hyperbolic dependence on the $2^{\prime}$ dGTP concentration; Km, rate constant $k$ and the stretching parameter $\beta$ were shared by all curves in the dataset. A detailed description of the data analyses is presented in Supplementary Note.

Docking experiments. An RNAP fragment comprising amino acid residues and the template DNA within $20 \AA$ from the active-site-bound CMPCPP was extracted from the X-ray crystal structure of the initiation complex of $T$. thermophilus RNAP (PDB ID 4Q4Z) ${ }^{18}$. The substrate binding site was vacated by removing CMPCPP. $3 \mathrm{D}$ structures of the $3^{\prime}$-endo CTP, $3^{\prime}$-endo $2^{\prime} \mathrm{dCMPNPP}$, and $2^{\prime}$-endo $2^{\prime} \mathrm{dCMP}$ were extracted from PDB ID 3BSO $(1.74 \AA)^{46}, 4 \mathrm{O} 3 \mathrm{~N}(1.58 \AA)^{47}$, and 3FL6 $(1.17 \AA)^{48}$, respectively. Phosphate moieties were rebuilt using Discovery Studio 4.5 (Accelrys, San Diego, CA, USA) to produce $3^{\prime}$-endo CTP, CMP, $2^{\prime} \mathrm{dCTP}, 2^{\prime} \mathrm{dCMP}, 2^{\prime}$-endo $2^{\prime}$ $\mathrm{dCTP}$, and $2^{\prime} \mathrm{dCMP}$. Ligands and the RNAP fragment were prepared for docking using AutoDock tools ${ }^{49}$. AutoDock Vina 1.1.2 docking runs were performed in a $16 \times 20 \times 20 \AA$ search space centered at $183,6,83 \AA$ (coordinate space of PDB ID $4 \mathrm{Q} 4 \mathrm{Z}$ ) using the default scoring function ${ }^{50}$. The docking was performed using 12 simultaneous computational threads; 20 binding poses were recorded for each run. Binding poses involving Watson-Crick pairing between the substrate and the template DNA (templated poses) were manually selected and extracted for further analysis (Supplementary Table 3). Our initial docking trials revealed that docking of nucleoside monophosphates produced the most robust and quantitatively interpretable results. Thus, the docking algorithm failed to recover templated poses for nucleosides without phosphate groups. The docking algorithm also failed to position the triphosphate moiety to coordinate metal ion number two and instead attempted to maximize its contacts with the protein. As a result, the recovered conformations of the triphosphate moieties differed from those observed in crystal structures. Considering the high impact of the triphosphate moiety on the ligand binding score and our assessment that the triphosphate moiety was docked incorrectly, we opted to limit the systematic investigation of the interaction between RNAP and the sugar moieties of nucleosides to docking nucleoside monophosphates.

Preparation of the promoter DNA scaffold for the crystallization. The non template DNA strand (5'-TATAATGGGAGCTGTCACGGATGCAGG- $3^{\prime}$ ) was annealed to the template DNA strand (5'-CCTGCATCCGTGAGTGCAGCCA-3') in $40 \mu \mathrm{l}$ of $10 \mathrm{mM}$ Tris- $\mathrm{HCl}(\mathrm{pH} 8.0), 50 \mathrm{mM} \mathrm{NaCl}$, and $1 \mathrm{mM}$ EDTA to the final concentration of $1 \mathrm{mM}$. The solution was heated at $95^{\circ} \mathrm{C}$ for $10 \mathrm{~min}$ and then gradually cooled to $22^{\circ} \mathrm{C}$.

Crystallization of the T. thermophilus RNAP initially transcribing complexes. The crystals of the RNAP and promoter DNA complex were prepared as described previously ${ }^{51,52}$. The RNAP and promoter DNA complex was prepared by mixing $24 \mu \mathrm{l}$ of $18 \mu \mathrm{M}$ T. thermophilus holoenzyme (in $20 \mathrm{mM}$ Tris-HCl, $\mathrm{pH}$ 7.7, $100 \mathrm{mM}$ $\mathrm{NaCl}$, and $1 \%$ glycerol) and $0.65 \mu \mathrm{l}$ of $1 \mathrm{mM} \mathrm{DNA}$ scaffold and incubated for 30 min at $22{ }^{\circ} \mathrm{C}$. Crystals were obtained by using hanging drop vapor diffusion by mixing equal volume of RNAP-DNA complex solution and crystallization solution (100 mM Tris-HCl, pH 8.7, $200 \mathrm{mM} \mathrm{KCl,} 50 \mathrm{mM} \mathrm{MgCl}_{2}, 10 \mathrm{mM}$ Spermine tetra$\mathrm{HCl}$, and $10 \%$ PEG 4000) and incubating at $22^{\circ} \mathrm{C}$ over the same crystallization solution. The crystals were cryoprotected by soaking in same constituents as the crystallization solution with stepwise increments of PEG4000 and (2R,3R)(-)-2,3-butanediol (Sigma-Aldrich) to final concentrations of $25 \%$ and $15 \%$, respectively. The crystals were sequentially transferred to the final cryoprotection solution containing $1 \mathrm{mM}$ primer $5^{\prime}-\mathrm{GpCpA}-3^{\prime}$ for $1 \mathrm{~h}$ and then transferred to the cryoprotection solution containing either $4 \mathrm{mM} 2^{\prime} \mathrm{dCTP}$ or $3^{\prime} \mathrm{dCTP}$ for $30 \mathrm{~s}$ to trap the pre-catalytic complexes. The crystals were harvested and flash frozen in liquid nitrogen.

X-ray data collections and structure determinations. The X-ray datasets were collected at the Macromolecular Diffraction at the Cornell High Energy Synchrotron Source (MacCHESS) F1 beamline (Cornell University, Ithaca, NY, USA) and structures were determined as previously described ${ }^{51,52}$ using the following crystallographic software: HKL2000 ${ }^{53}$, Phenix ${ }^{54}$, and $\operatorname{Coot}^{55}$. Structure figures were prepared using PyMOL (Schrödinger, LLC, New York, NY, USA).

Reporting summary. Further information on research design is available in the Nature Research Reporting Summary linked to this article.

\section{Data availability}

The data that support this study are available from the corresponding authors upon reasonable request. X-ray crystallographic structure coordinates and their structural factors have been deposited in the RCSB Protein Data Bank (https://www.rcsb.org/) with accession codes 6WOX and 6WOY. Source data are provided with this paper.

Received: 24 June 2020; Accepted: 6 January 2021; Published online: 04 February 2021

\section{References}

1. Gilbert, W. Origin of life: the RNA world. Nature 319, 618 (1986).

2. Joyce, G. F. The antiquity of RNA-based evolution. Nature 418, 214-221 (2002).

3. Zhang, N., Zhang, S. \& Szostak, J. W. Activated ribonucleotides undergo a sugar pucker switch upon binding to a single-stranded RNA template. J. Am. Chem. Soc. 134, 3691-3694 (2012)

4. Nakamura, T., Zhao, Y., Yamagata, Y., Hua, Y. \& Yang, W. Watching DNA polymerase $\eta$ make a phosphodiester bond. Nature 487, 196-201 (2012).

5. Traut, T. W. Physiological concentrations of purines and pyrimidines. Mol. Cell. Biochem. 140, 1-22 (1994). 
6. Nick McElhinny, S. A. et al. Abundant ribonucleotide incorporation into DNA by yeast replicative polymerases. Proc. Natl Acad. Sci. USA 107, 4949-4954 (2010).

7. Uptain, S. M., Kane, C. M. \& Chamberlin, M. J. Basic mechanisms of transcript elongation and its regulation. Annu. Rev. Biochem. 66, 117-172 (1997).

8. Brown, J. A. \& Suo, Z. Unlocking the sugar "steric gate" of DNA polymerases. Biochemistry 50, 1135-1142 (2011).

9. Sousa, R. \& Padilla, R. A mutant T7 RNA polymerase as a DNA polymerase. EMBO J. 14, 4609-4621 (1995).

10. Huang, Y., Eckstein, F., Padilla, R. \& Sousa, R. Mechanism of ribose $2^{\prime}$-group discrimination by an RNA polymerase. Biochemistry 36, 8231-8242 (1997).

11. Yin, Y. W. \& Steitz, T. A. The structural mechanism of translocation and helicase activity in T7 RNA polymerase. Cell 116, 393-404 (2004).

12. Gleghorn, M. L., Davydova, E. K., Basu, R., Rothman-Denes, L. B. \& Murakami, K. S. X-ray crystal structures elucidate the nucleotidyl transfer reaction of transcript initiation using two nucleotides. Proc. Natl Acad. Sci. USA 108, 3566-3571 (2011).

13. Joyce, C. M. Choosing the right sugar: how polymerases select a nucleotide substrate. Proc. Natl Acad. Sci. USA 94, 1619-1622 (1997).

14. Li, Y., Korolev, S. \& Waksman, G. Crystal structures of open and closed forms of binary and ternary complexes of the large fragment of Thermus aquaticus DNA polymerase I: structural basis for nucleotide incorporation. EMBO J. 17, 7514-7525 (1998).

15. Betz, K. et al. KlenTaq polymerase replicates unnatural base pairs by inducing a Watson-Crick geometry. Nat. Chem. Biol. 8, 612-614 (2012).

16. Belogurov, G. A. \& Artsimovitch, I. The mechanisms of substrate selection, catalysis, and translocation by the elongating RNA polymerase. J. Mol. Biol. 431, 3975-4006 (2019).

17. Cheung, A. C. M., Sainsbury, S. \& Cramer, P. Structural basis of initial RNA polymerase II transcription. EMBO J. 30, 4755-4763 (2011).

18. Basu, R. S. et al. Structural basis of transcription initiation by bacterial RNA polymerase holoenzyme. J. Biol. Chem. 289, 24549-24559 (2014).

19. Maffioli, S. I. et al. Antibacterial nucleoside-analog inhibitor of bacterial RNA polymerase. Cell 169, 1240-1248.e23 (2017).

20. Wang, D., Bushnell, D. A., Westover, K. D., Kaplan, C. D. \& Kornberg, R. D. Structural basis of transcription: role of the trigger loop in substrate specificity and catalysis. Cell 127, 941-954 (2006).

21. Vassylyev, D. G. et al. Structural basis for substrate loading in bacterial RNA polymerase. Nature 448, 163-168 (2007).

22. Yuzenkova, Y. et al. Stepwise mechanism for transcription fidelity. BMC Biol. 8, 54 (2010).

23. Zhang, J., Palangat, M. \& Landick, R. Role of the RNA polymerase trigger loop in catalysis and pausing. Nat. Struct. Mol. Biol. 17, 99-104 (2010).

24. Kaplan, C. D., Larsson, K.-M. \& Kornberg, R. D. The RNA polymerase II trigger loop functions in substrate selection and is directly targeted by alphaamanitin. Mol. Cell 30, 547-556 (2008).

25. Svetlov, V., Vassylyev, D. G. \& Artsimovitch, I. Discrimination against deoxyribonucleotide substrates by bacterial RNA polymerase. J. Biol. Chem. 279, 38087-38090 (2004)

26. Zhang, Y. et al. GE23077 binds to the RNA polymerase " $i$ " and " $i+1$ " sites and prevents the binding of initiating nucleotides. Elife 3, e02450 (2014).

27. Roßbach, S. \& Ochsenfeld, C. Quantum-chemical study of the discrimination against dNTP in the nucleotide addition reaction in the active site of RNA polymerase II. J. Chem. Theory Comput. 13, 1699-1705 (2017).

28. Turtola, M. \& Belogurov, G. A. NusG inhibits RNA polymerase backtracking by stabilizing the minimal transcription bubble. Elife 5, e18096 (2016).

29. Malinen, A. M. et al. Active site opening and closure control translocation of multisubunit RNA polymerase. Nucleic Acids Res. 40, 7442-7451 (2012).

30. Gohara, D. W., Arnold, J. J. \& Cameron, C. E. Poliovirus RNA-dependent RNA polymerase (3Dpol): kinetic, thermodynamic, and structural analysis of ribonucleotide selection. Biochemistry 43, 5149-5158 (2004).

31. Kireeva, M. L. et al. Transient reversal of RNA polymerase II active site closing controls fidelity of transcription elongation. Mol. Cell 30, 557-566 (2008).

32. Batra, V. K. et al. Magnesium-induced assembly of a complete DNA polymerase catalytic complex. Structure 14, 757-766 (2006).

33. Kozlov, I. A. \& Orgel, L. E. Nonenzymatic template-directed synthesis of RNA from monomers. Mol. Biol. 34, 781-789 (2000).

34. Iyer, L. M., Koonin, E. V. \& Aravind, L. Evolutionary connection between the catalytic subunits of DNA-dependent RNA polymerases and eukaryotic RNAdependent RNA polymerases and the origin of RNA polymerases. BMC Struct. Biol. 3, 1 (2003).

35. Salgado, P. S. et al. The structure of an RNAi polymerase links RNA silencing and transcription. PLoS Biol. 4, e434 (2006).

36. Samanta, B. \& Joyce, G. F. A reverse transcriptase ribozyme. Elife 6, e31153 (2017).

37. $\mathrm{Xu}$, J. et al. Selective prebiotic formation of RNA pyrimidine and DNA purine nucleosides. Nature 582, 60-66 (2020).
38. Gong, P. \& Peersen, O. B. Structural basis for active site closure by the poliovirus RNA-dependent RNA polymerase. Proc. Natl Acad. Sci. USA 107 22505-22510 (2010)

39. Wang, Q. et al. Structural basis for RNA replication by the SARS-CoV-2 polymerase. Cell 182, 417-428.e13 (2020).

40. Yin, W. et al. Structural basis for inhibition of the RNA-dependent RNA polymerase from SARS-CoV-2 by remdesivir. Science 368, 1499-1504 (2020).

41. Svetlov, V. \& Artsimovitch, I. Purification of bacterial RNA polymerase: tools and protocols. Methods Mol. Biol. 1276, 13-29 (2015).

42. Komissarova, N., Kireeva, M. L., Becker, J., Sidorenkov, I. \& Kashlev, M. Engineering of elongation complexes of bacterial and yeast RNA polymerases. Methods Enzymol. 371, 233-251 (2003).

43. Abramoff, M. D., Magalhaes, P. J. \& Ram, S. J. Image processing with ImageJ. Biophotonics Int. 11, 36-42 (2004).

44. Johnson, K. A. Fitting enzyme kinetic data with KinTek Global Kinetic Explorer. Methods Enzymol. 467, 601-626 (2009).

45. Prajapati, R. K. et al. Oxazinomycin arrests RNA polymerase at the polythymidine sequences. Nucleic Acids Res. 47, 10296-10312 (2019).

46. Zamyatkin, D. F. et al. Structural insights into mechanisms of catalysis and inhibition in Norwalk virus polymerase. J. Biol. Chem. 283, 7705-7712 (2008)

47. Patra, A. et al. Kinetics, structure, and mechanism of 8-Oxo-7,8-dihydro-2' deoxyguanosine bypass by human DNA polymerase $\eta$. J. Biol. Chem. 289, 16867-16882 (2014)

48. Robeyns, K., Herdewijn, P. \& Van Meervelt, L. Direct observation of two cyclohexenyl (CeNA) ring conformations in duplex DNA. Artif. DNA PNA XNA 1, 2-8 (2010).

49. Morris, G. M. et al. AutoDock4 and AutoDockTools4: automated docking with selective receptor flexibility. J. Comput. Chem. 30, 2785-2791 (2009).

50. Trott, O. \& Olson, A. J. AutoDock Vina: improving the speed and accuracy of docking with a new scoring function, efficient optimization, and multithreading. J. Comput. Chem. 31, 455-461 (2010).

51. Murakami, K. S., Shin, Y., Turnbough, C. L. \& Molodtsov, V. X-ray crystal structure of a reiterative transcription complex reveals an atypical RNA extension pathway. Proc. Natl Acad. Sci. USA 114, 8211-8216 (2017).

52. Shin, Y., Hedglin, M. \& Murakami, K. S. Structural basis of reiterative transcription from the pyrG and pyrBI promoters by bacterial RNA polymerase. Nucleic Acids Res. 48, 2144-2155 (2020).

53. Otwinowski, Z. \& Minor, W. Processing X-ray diffraction data collected in oscillation mode. Methods Enzymol. 276, 307-326 (1997).

54. Afonine, P. V. et al. Joint X-ray and neutron refinement with phenix.refine. Acta Crystallogr. D Biol. Crystallogr. 66, 1153-1163 (2010).

55. Emsley, P. \& Cowtan, K. Coot: model-building tools for molecular graphics. Acta Crystallogr. D Biol. Crystallogr. 60, 2126-2132 (2004).

\section{Acknowledgements}

We thank Irina Artsimovitch for critically reading the manuscript, the staff at the MacCHESS for support of crystallographic data collection, Anssi M. Malinen for constructing plasmids, and Matti Turtola for his contribution to the development of the EDTA quench method. This work was supported by Academy of Finland Grant 286205 to G.A.B., NIH grants R01 GM087350 and R35 GM131860 to K.S.M. and Sigrid Jusélius Foundation grant 1702 to M.M-K. and G.A.B.

\section{Author contributions}

J.J.M. and E.V. performed the biochemical analysis of E. coli RNAPs. K.S.M. and Y.S. solved the X-ray structures of T. thermophilus RNAP. G.A.B. performed the in silico docking experiments. All authors contributed to the analysis of the data and the interpretation of the results. G.B. and K.S.M. wrote the manuscript with contributions from the other authors.

\section{Competing interests}

The authors declare no competing interests.

\section{Additional information}

Supplementary information The online version contains supplementary material available at https://doi.org/10.1038/s41467-021-21005-w.

Correspondence and requests for materials should be addressed to K.S.M. or G.A.B.

Peer review information Nature Communications thanks the anonymous reviewers for their contribution to the peer review of this work. Peer reviewer reports are available.

Reprints and permission information is available at http://www.nature.com/reprints

Publisher's note Springer Nature remains neutral with regard to jurisdictional claims in published maps and institutional affiliations. 
(c) (i) Open Access This article is licensed under a Creative Commons Attribution 4.0 International License, which permits use, sharing, adaptation, distribution and reproduction in any medium or format, as long as you give appropriate credit to the original author(s) and the source, provide a link to the Creative Commons license, and indicate if changes were made. The images or other third party material in this article are included in the article's Creative Commons license, unless indicated otherwise in a credit line to the material. If material is not included in the article's Creative Commons license and your intended use is not permitted by statutory regulation or exceeds the permitted use, you will need to obtain permission directly from the copyright holder. To view a copy of this license, visit http://creativecommons.org/ licenses/by/4.0/.

(C) The Author(s) 2021 